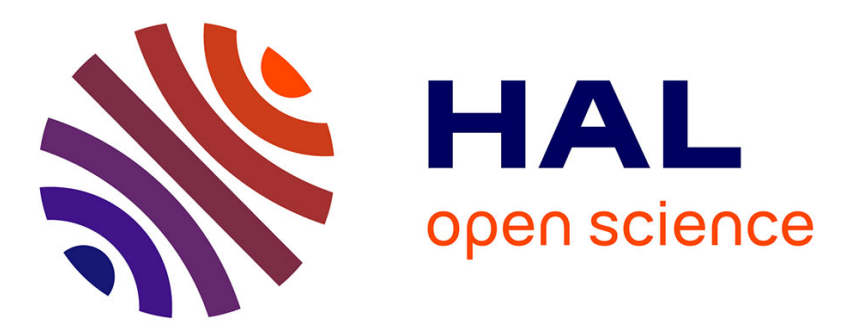

\title{
Dossier des fouilles du sanctuaire lyonnais de Cybèle et de ses abords
}

\author{
Amable Audin
}

\section{To cite this version:}

Amable Audin. Dossier des fouilles du sanctuaire lyonnais de Cybèle et de ses abords. Gallia - Fouilles et monuments archéologiques en France métropolitaine, 1985, 43 (1), pp.81-126. 10.3406/galia.1985.2822 . hal-01940084

\section{HAL Id: hal-01940084 \\ https://hal.science/hal-01940084}

Submitted on 27 Feb 2020

HAL is a multi-disciplinary open access archive for the deposit and dissemination of scientific research documents, whether they are published or not. The documents may come from teaching and research institutions in France or abroad, or from public or private research centers.
L'archive ouverte pluridisciplinaire HAL, est destinée au dépôt et à la diffusion de documents scientifiques de niveau recherche, publiés ou non, émanant des établissements d'enseignement et de recherche français ou étrangers, des laboratoires publics ou privés.

\section{(이) $\$$}

Distributed under a Creative Commons Attribution - NonCommercial - NoDerivatives 44.0 


\title{
DOSSIER DES FOUILLES DU SANCTUAIRE LYONNAIS DE CYBËLE ET DE SES ABORDS
}

\author{
par Amable AUDIN
}

\section{LES ÉLÉMENTS D'UNE TRADITION}

Au cours d'une période qui pour le moins s'étend de l'année 160 à l'année 212, Lugdunum fut le foyer d'une intense activité religieuse autour du culte de Cybèle1. Sous le titre de Magna Mater deum Idaeae Augusta, la déesse phrygienne était adorée dans un sanctuaire d'où proviennent six autels tauroboliques, ou plutôt sept, si l'on tient pour lyonnais celui qui dut être transporté à Tain par des mariniers du Rhône. Cinq, dont celui de Tain, consacrent expressément un sacrifice offert pour le maintien de la colonie de Lugdunum. Les quatre, que les mutilations ont partiellement respectés, précisent que le lieu où ils s'érigaient avait été offert par les décurions de la même colonie. Dans l'agglomération multicéphale du confluent, la colonie de Lugdunum étant spécifiquement la ville qui occupait la colline de Fourvière, c'en est assez pour supposer que ce sanctuaire s'érigeait à Fourvière. Le problème est de l'y retrouver.

Les autels tauroboliques lyonnais, sauf un, furent retaillés au cube à fin de réemploi dans des édifices médiévaux. Ils perdirent ainsi tout ou partie des moulurations de tête et de pied avec les figures en relief qui les ornaient. Gravés en creux, les textes demeurent heureusement lisibles. Ces réemplois entraînèrent naturellement le déplacement des blocs : deux ont été retrouvés dans une arche du pont de la Saône, un autre dans le lit de la rivière, un quatrième fut recueilli on ne sait où et porté dans une collection privée. Rien de tout ceci ne permet de situer le foyer de la religion métroaque. Plus significatif à cet égard, un cinquième autel fut retrouvé à Fourvière, dans l'actuel chantier archéologique, mais déjà déplacé et retaillé pour un réemploi qui ne fut pas réalisé, sans doute parce qu'il n'en était

1 A. Avnis, Le sanctiatire de cijbète et les autels taurobotiques de Lyon, dans lievue du Lyonnuis, i978, 4, p. 193 200. - Le présent article a pour but de faire connaître le dossier de la question : historique, fouilles, description des vestiges exhumés, illustrations; avec les possibilités d'une restitution. Il ne prétend pas apporter l'étude comparative qui reste à faire. Les données recueillies par les fouilles de l'entourage de l'édifice ont été jointes aux premières : elles apportent des renseignements précieux sur l'installation de l'ensemble. 


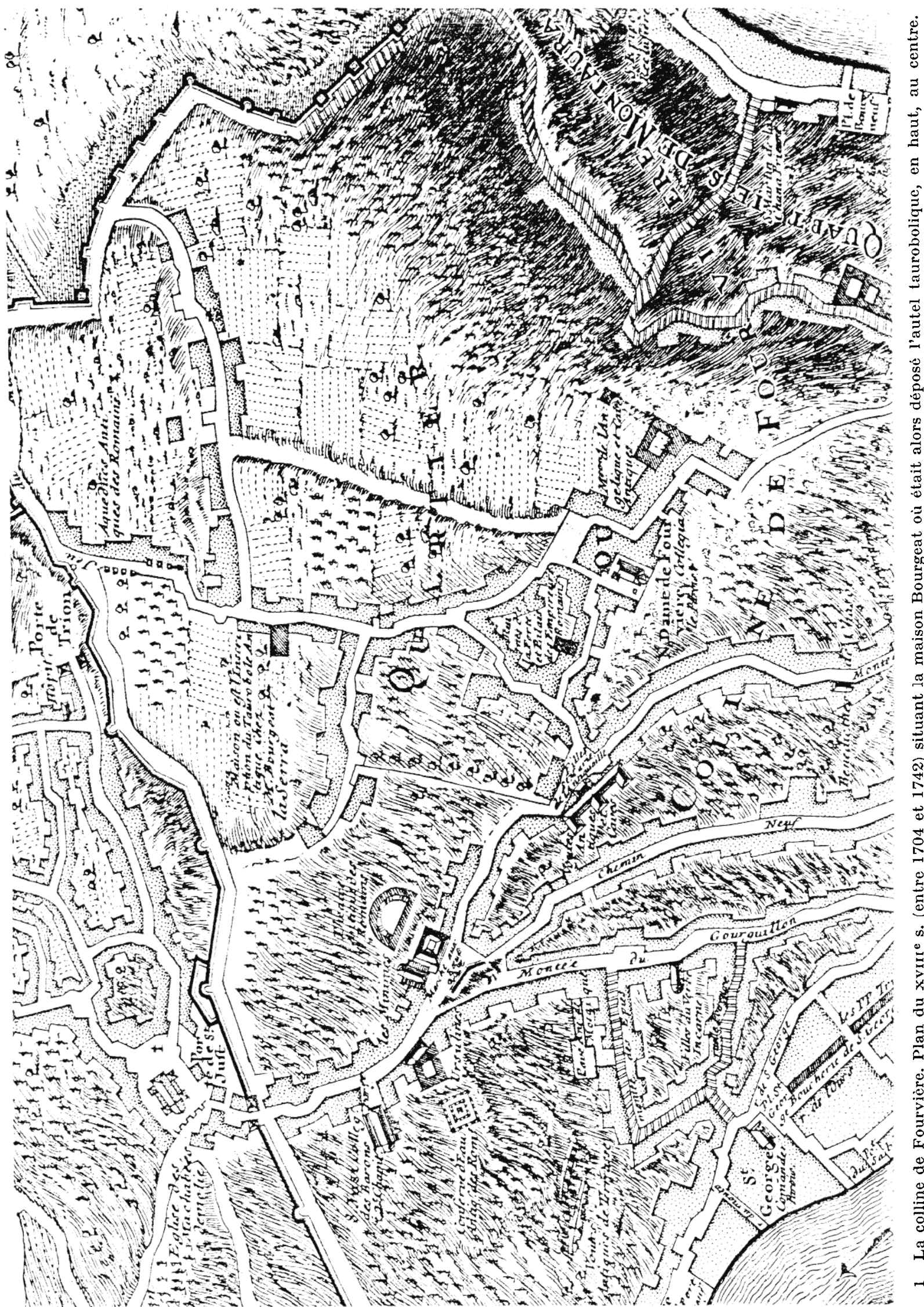


plus besoin, soit dans le pont de la Saône, soit dans la cathédrale, deux entreprises qui, aux XII ${ }^{\mathrm{e}}$ et XIII ${ }^{\mathrm{e}} \mathrm{s}$, furent grandes consommatrices de blocs antiques.

Reste le dernier, le plus ancien en fait, daté de 160 . Il ne subit aucune mutilation pour réemploi, ce qui offre une raison légitime, mais point unique, de penser qu'il ne quitta jamais le licu où il fut retrouvé ${ }^{2}$ en décembre 1704. La localisation précise de cette découverte est si essentielle pour la présente étude qu'il convient de reprendre les pièces d'un procès dû à la confusion que provoqua la retranscription inconsidérée de documents initialement corrects.

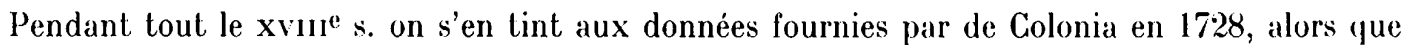
l'autel, qui sera acquis par la Ville en 1742 seulement, était encore en place : sur la colline de Fourvière, près de l'église, dans la vigne Bourgeat ${ }^{3}$ (fig. 1). Bourgeat disparu, la crainte que l'on oubliât le lieu où était apparu l'autel incita Artaud à en rajeunir la localisation. Entre 1794 et 18:36, période au cours de laquelle il rassembla les matériaux de son "Lyon soulerrain", it écrivit, non sans quelque légèreté : "C'est vis-à-vis la partie méridionale du forum et au-dessus du théître, dans la maison qui a appartenu à M. Bourgeat, et que possède M. Marc-Antoine de Nolhac, qu'on a découvert, en 1704, le fameux taurobole d'Antonin "4. Intervention malheureuse. Artaud engageait ainsi un processus de désagrégation dont nous ne sommes pas totalement libérés. Ce qu'il nommait la partie méridionale du forum est le mur Cléberg, sans liaison avec le forum. Le théâtre n'ayant été identifié qu'en 1934, l'édifice auquel il attribue ce tilre est nécessairement l'odéon. En 1854, de Boissieu, revenant à des données plus pondérées, reprenait simplement l'indication : "dans la vigne d'un M. Bourgeat, dont la propriété appartient aujourd'hui à M. M.-Ant. de Nolhac "s. Il eùt été mieux inspiré, à cette date, de préciser les limites de cette terre. Allmer, en 1888, réactualisait. l'ensemble de ces données en les amplifiant : «dans la vigne d'un sieur Bourgeat, dont la propriété appartient aujourd'hui à M. Marc-Antoine de Nolhac, derrière les ruines du théâtre antique qui se voient chez les Dames de la Compassion " ${ }^{6}$. A la suite de cette dernière précision, que devait entériner Hirrschfeld $^{7}$, le souvenir des noms des propriétaires successivement eflacés, un retint seulement que l'autel avait été trouvé derrière l'odéon, lequel était en effet chez les Dames de la Compassion.

Il fallut attendre la scrupuleuse intervention de Philippe Fabia pour pouvoir lire, en 1934, dans une note trop modeste en bas de page, concernant le clos Bourgeat : "actuellement partie s. de l'orphelinat de Fourvière, rue du Juge-de-Paix ${ }^{8}$. On tint d'autant moins compte de cette discrète mais efficace mise au point que, peu après la parution de sa note, n'existaient plus ni orphelinat de Fourvière, devenu Institution de la Voie romaine, ni rue du Juge-de-Paix, rebaptisée rue RogerRadisson. Si totale était alors l'incertitude que Charles Picard pouvait émettre cette opinion, destinée à clore le débat : "Les vestiges signalés à Lyon au-dessus du théâtre de Fourvière, et qui ont été interprétés comme ceux d'un sanctuaire de Cybèle, n'offrent aucune particularité démonstrative : l'identification a été d'ailleurs surtout proposée en raison de documents dont l'emplacement primitif n'est pas assuré ». Ces «documents " sont, à l'évidence, l'autel de 1704, et l'incertitude qui affecte le site de sa découverte est le résultat des errements signalés plus haut.

2 C.I.L., XII, $1782 ;$ XIII, 1751 à 1756.

3 Gros de Boze, Explicalion d'une inscription antique trouvee depuis peu à Lyon, Paris, 1705. - Ve Coloxis, Hisloire littéraire de la Ville de Lyon, I, p. 186. - ID., Dissertalion sur un monument anlique découvert à Lyon sur la montagne de Fourvière au mois de décembre 1704, 1,yon, 1705.

4 F. ARTAvin, Lyon somlerrain, 1.yon, 1846, p. 11.

5) A. в: Bolssivu, Inseriptions anliques de l.yon, Lyon, 1854, p. 23.

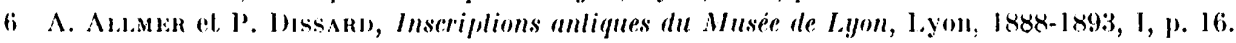

7 C.I.L., XI11, 1751.

$\checkmark$ Ph. FAB1A, Pierre Sialn et l'Antiquaille, Lyon, 1934, p. 280, n. 1. 
Reprenant les choses à la base, il convient aujourd'hui d'identifier à nouveau et définitivement ce que fut la vigne Bourgeat.

Si l'on se reporte à telle carte de $1737^{\circ}$, antérieure donc de 5 ans à l'achat de l'autel par la Municipalité, la vigne Bourgeat est limitée, au n., par le "Chemin lendant des ares à l'Église de Saint Thomas de Fourvière, ou de Lyon à la recluscric Sainte Marg.te ", actuelle rue Roger-Radisson, qui va précisément des aqueducs de la porte de Trion à la basilique actuelle et à la chapelle Saint-Thomas; à l'o. par la "Vigne des Dames religieuses de l'Anticaille ", aujourd'hui le clos du Carmel; au s. par la "Vigne du Sr Vernay ", actuellement propriété de la ville, dont l'angle n.-e. était déjà occupé par la maison dite "des Cèdres", qui domine le chantier archéologique; enfin, le côté e. était déterminé par la «Ruette allant aux vignes des Belettes", parfois nommée ruelle de Jaleyse, qui, sous la dénomination dérisoire de rue Munatius-Plancus est apparue sur tels plans de Lyon, sans jamais dépasser le stade des projets. Cette ruelle subsista jusqu'en 1974, date de l'intégration de l'ancienne vigne Bourgeat au chantier archéologique.

Ainsi, tout est parfaitement clair. Le lieu où reparut l'autel de 1704 est défini avec toute la finesse souhaitable, les dimensions modestes de la vigne étant encore réduites par l'encombrement des bâtiments bordant la rue, cette maison Bourgeat où l'autel avait été promptement abrité.

\section{LA MENTION D'UN CASTELLUM BUCIUM}

Les textes médiévaux, transmis par les historiens de la Renaissance, citent à l'envi, sur la colline de Fourvière, un édifice qu'ils nomment Castellum Bucium. Le second terme peut sembler ambigu. Si, en latin classique, le nom du bœuf est bos-bovis, les termes buculusbucula, "bouvillon " et "génisse », bucelum "pacage à bœufs »", émanent d'un radical bu. De ce terme dériverait tout naturellement le qualificatif bucium que le Moyen-Âge attribuait à l'édifice où se voyait l'image d'un taureau. Cet argument séduisant ne prendrait un sens que si était démontrée l'identité du castellum Bucium avec les vestiges d'où fut tiré l'autel de 160. Or, précisément, la localisation de ce castellum fait l'objet de controverses.

Au premier contact, les textes déçoivent par leur imprécision. Paradin qui, en 1573, a publié le résultat de ses recherches, se contente d'abord d'affirmer que les vestiges "qui s'étendent par loutes les vignes de ceste montagne sont nommées es pancartes Castellum Bucium "11. Il devient plus précis lorsqu'il situe une vigne prope forum vetus ad Castellum scilicel Bucium ${ }^{12}$. Forum vetus, c'est notre place de Fourvière dilatée sur les quatre faces. Les choses prennent plus de consistance quand il déclare que n'étaient visibles, au-dessus de la Croix de Colle - notre place des Minimes -, que deux édifices antiques : l'amphithéâtre (l'odéon) et le Castellum Bucium dont il écrit: «Il y en a aussi qui ont esté d'opinion que c'estoit le palais de Severus. Tant y a que ce povoit bien estre l'un et l'autre, et que le palais estoit contigu à l'amphithéâtre, comme l'on void dedans les maisons des princes des lices pour les joustes et des hippodromes " ${ }^{13}$. Selon Paradin, donc, le Ghâtel Boc se

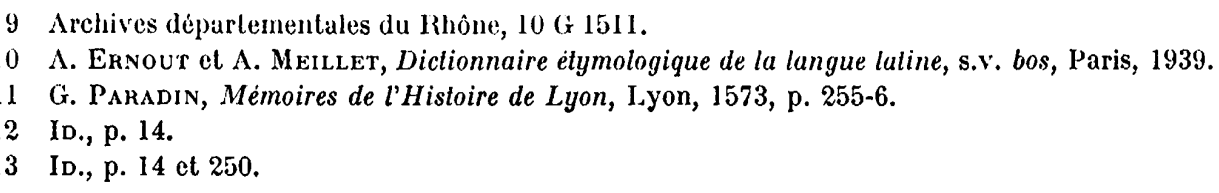


localise à côté de l'odéon, mais aussi près du forum. De plus, une précision topique émane du terrier Valentin du Grand Comté : "au territoire de Fourvière appelé Châtel Boc, jouxte le chemin qui va de l'église de Fourvière aux murs de la Ville ${ }^{14}$. Ce chemin étant sans conteste notre rue RogerRadisson ${ }^{15}$, le Châtel Boc est à rechercher entre cette rue et l'odéon. Localisation si conforme à celle de la vigne Bourgeat que l'on n'a guère de peine à se persuader que l'autel de 160 provient précisément du Castellum Bucium.

Positif du point de vue topographique, le témoignage de Paradin est également riche du point de vue chronologique. Remontant le cours du temps, il note que le Castellum Bucium était cité à l'époque de l'abbé de Saint-Just Ademarus, vers 1010. A cette date, ce n'était pas le seul autel de 160 qui attirait le regard, mais un grand nombre d'autels à bucranes qui lui méritaient d'autant mieux le titre de bucium. De ce point de vue, la mention de Septime Sévère n'est pas à dédaigner. On se gardera d'oublier telle observation d'Artaud relative au même édifice : "Les gens du peuple racontent qu'il y avait eu en cet endroit (le castellum Bucium) un veau d'or enseveli auquel Auguste rendait les honneurs divins $\|^{16}$. Le veau, disons le taureau, que l'empereur aurait honoré n'est-il pas celui des sacrifices tauroboliques commémorés par les autels à bucranes, dont la dédicace s'ouvrait sur le nom du prince? Antérieurement aux $\mathrm{xII}^{\mathrm{e}}$ et $\mathrm{xIII}^{\mathrm{e}} \mathrm{s}$. et au démantelement de l'édifice, c'est toute une collection d'autels semblables qui affirmaient la présence de l'animal, en relation avec Auguste et, au moins pour trois d'entre eux, avec Severus ${ }^{17}$.

Le terme de Castellum mérite aussi un commentaire. Il désigne un édifice d'aspect militaire, "un château fort " selon Artaud ${ }^{18}$. Il convient de retrouver les restes de cet édifice dans le clos Bourgeat.

\section{LE SANCTUAIRE}

\section{PREMIERES FOUILLES}

Sans doute parce que leur analyse des données relatives au culte de Ciybèle coïncidait avec celle qui vient d'être exposée, dès 1925, Philippe Fabia et C. Germain de Montauzan ouvrirent quelques tranchées exploratoires dans la partie s. du clos de l'orphelinat de Fourvière, laquelle n'était autre que l'ancien clos Bourgeat. Malheureusement, ces fouilles, limitées par la modicité des moyens comme par la présence des arbres fruitiers du verger, ne révélèrent que des vestiges qui furent qualifiés par leurs inventeurs de discontinus. Toutefois, parurent les puissantes substructions d'un mur épais de 1,50 m constituant, "mais sans certitude, la base d'un temple de Cybèle». A ces fouilleurs revient donc le mérite initial de l'identification de l'édifice. On leur reprochera seulement de n'avoir pas laissé un plan précis de leurs travaux, voire la possibilité de situer le mur de 1,50 m. Car on ne tiendra pas compte du plan signé Tardy, déposé au Musée Gadagne, à Lyon : il est tellement incertain qu'on le devine étayé sur de simples rapports verbaux, sans définition archéologique.

14 Arehives dẹnartementales dı Rhòne, fonds de Saint-Jean.

15 Ph. Fabia, loc. cit., p. 243-4.

16 F. Artaud, loc. cit., p. 11.

17 C.I.L., XIII, 1753, $1754,1755$.

18 F. Artaud, loc. cil., p. 11. 
Vers la fin de 1943, le dégagement de la voie dallée qui ceinture par l'o. la cauea du théâtre fit paraître un haut et large mur aveugle (fig. 2). Le dégagement total ne s'acheva qu'à la fin de 1946. Alors fut visible, dans la longueur de $52,79 \mathrm{~m}$, le soubassement oriental d'un édifice majestucux et surplombant, de surcroit assez complexe.

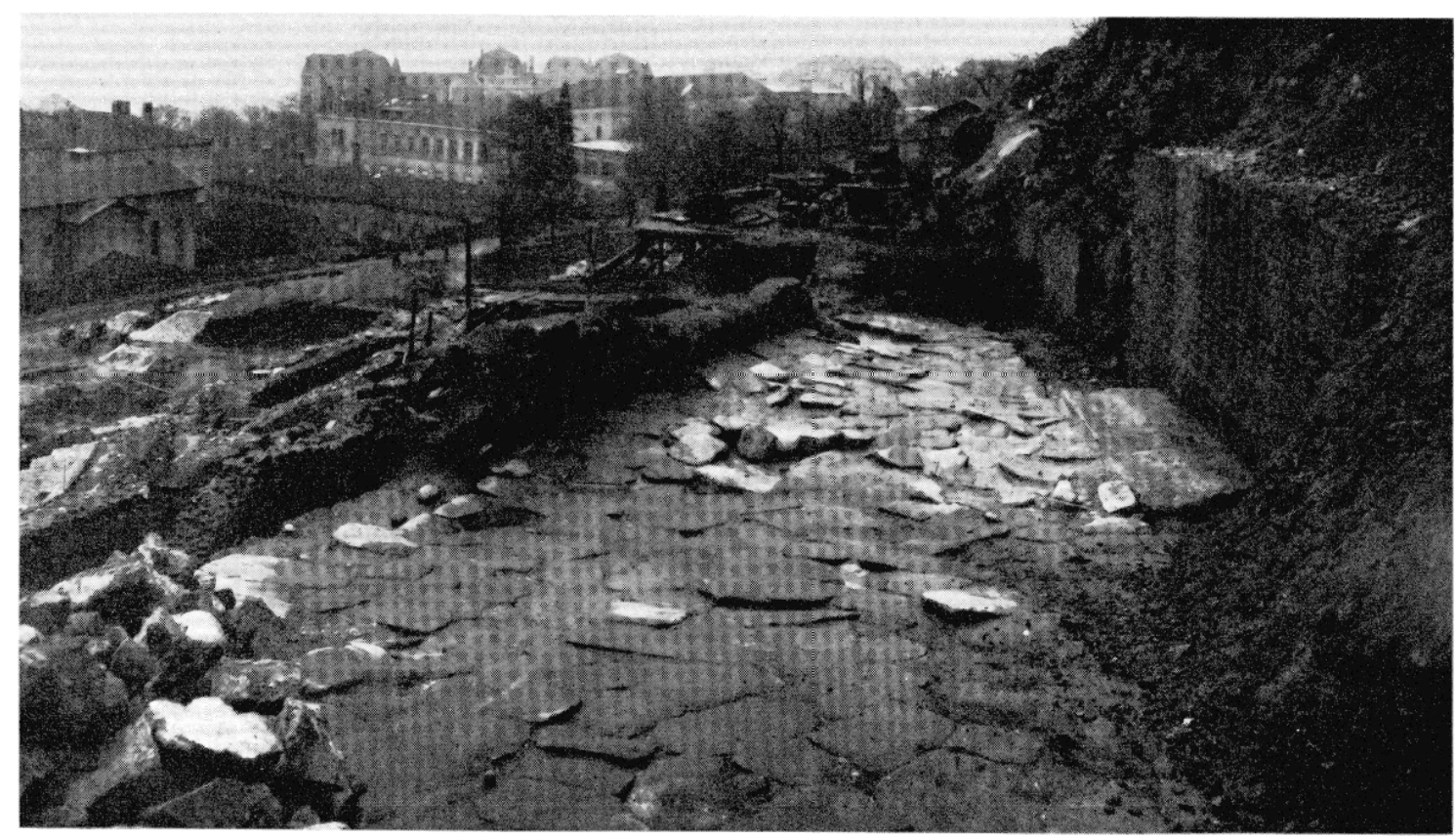

2 Le chemin dallé et le grand mur (à droite).

Ln massif central et compact, large de $13,35 \mathrm{~m}$, était encadré par deux ailes faites de trois alvćoles fermés du côté de la ruc. Le tout avait visiblement servi à porter au-dessus de la pente naturelle, en ce point fort accentuée, l'aire d'un monument établi sur le rebord du plateau. Dans cet ensemble maçonné, de grandes coupures verticales marquent l'emplacement de quatre chaînages de pierres de taille qui avaient conforté les deux angles du massif central et les deux angles extérieurs des ailes avant que ces blocs n'aient été exploités au Moyen- $\hat{A}$ ge. Peu après cette découverte, sur les 34 mètres dégagés de la façade s. de l'édifice, parurent quatre alvéoles semblables ct de même destination, se prolongcant à l'o., au-delà de la ruelle qui séparait le chantier de l'orphelinat. Dans les murs de moellons couraient de triples arases de briques. Ce mode de construction autorisait à dater le monument de la seconde moitić du II $^{\mathrm{e}}$ s. Alors n'hésita-t-on pas à lui attribuer le titre de sanctuaire de Cybèle, proposé vingt ans plus tôt par Fabia. La majeure partie de l'édificc demeurait malheureusement hors des limites du chantier archéologique, sous le verger de l'orphelinat, devenu Institution de la Voie romaine : impossible, dès lors, d'envisager un dégagement exhaustif.

Un projet d'élargissement de la rue Roger-Radisson impliquant la démolition de l'immeuble vétuste de l'ancien orphelinat, l'administration des Religieuses de Notre-Dame 
fit dresser le plan d'une nouvelle construction en reculement. Engagés au début du printemps 1965 , des sondages furent facilités par le repérage précis de l'angle n.-e. Il suffisait de suivre, à partir de là, le mur n. jusqu'à son extrémité. Il traversait sur toute sa longueur, à quelques mètres près, le clos de l'ancienne vigne Bourgeat, dans lequel le vaste édifice venait s'encastrer comme une boîte dans son couvercle. L'étendue et l'importance de l'édifice justifiaient un dégagement exhaustif qui fut achevé à la fin de 1974 (fig. 3). Des conclusions définitives pouvaient en être tirées.

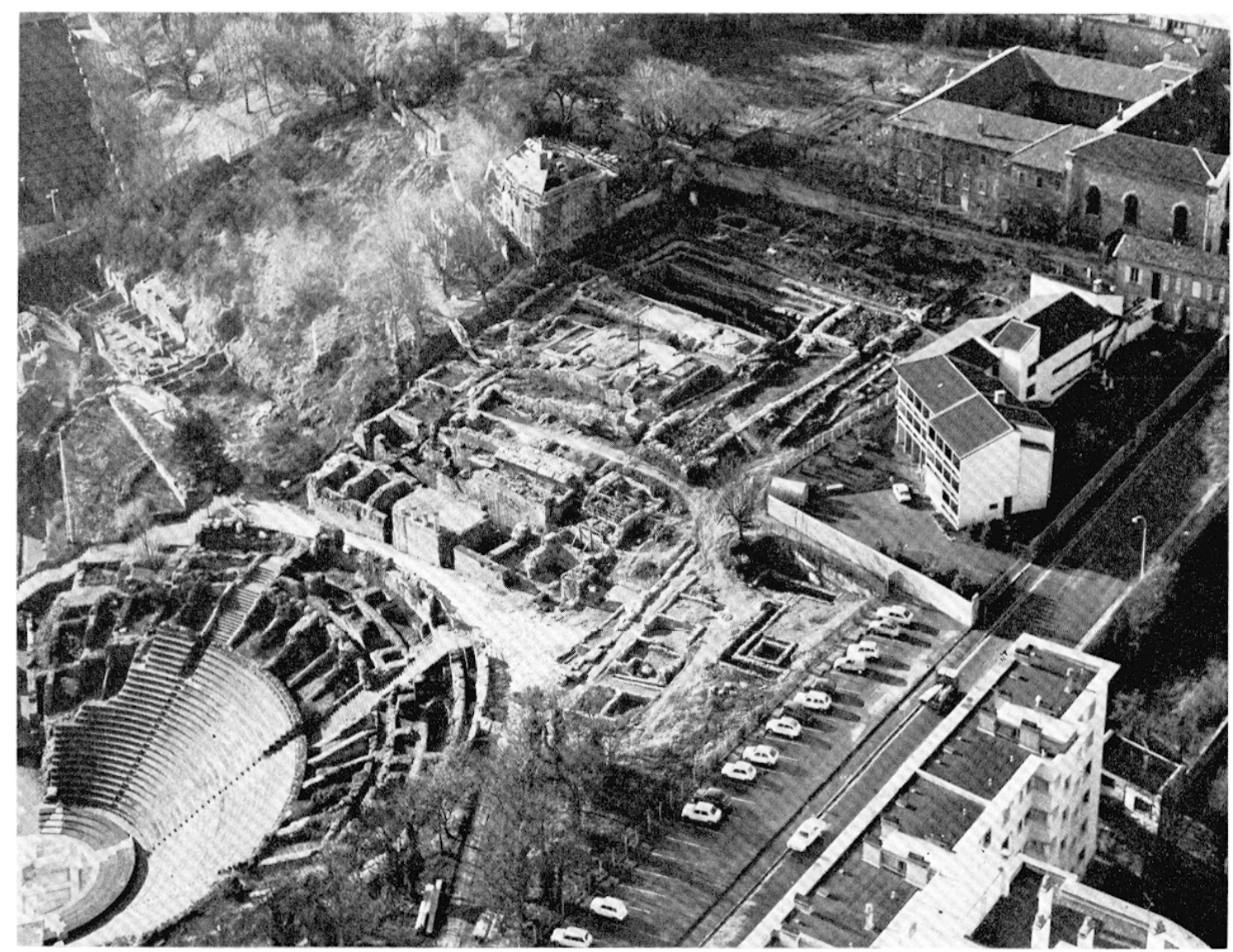

3 Le sanctuaire, état actuel (1982).

En fait, la destruction des parties extérieures du sanctuaire avait été totale : un seul bloc demeurait in situ et, compte tenu de l'exploitation systematique des pierres de taille pour réemploi, c'est miracle qu'un autel ait été préservé jusqu'en 1704, permettant une identification de l'édifice que l'on n'eût pas manqué de contester autrement. Se souvenant de la légende du Châtel Boc, on peut même se demander si cet unique autel ne fut pas laissé en place en souvenir du veau d'or. En revanche, les substructions, qui portaient les pierres de taille, faites de maçonneries non récupérables, ne furent pas spoliées par les constructeurs médiévaux. La partie o., assise sur le plateau, ne fut altérée que par la plantation d'arbres fruitiers qui entraìna la destruction de quelques portions de murs. 


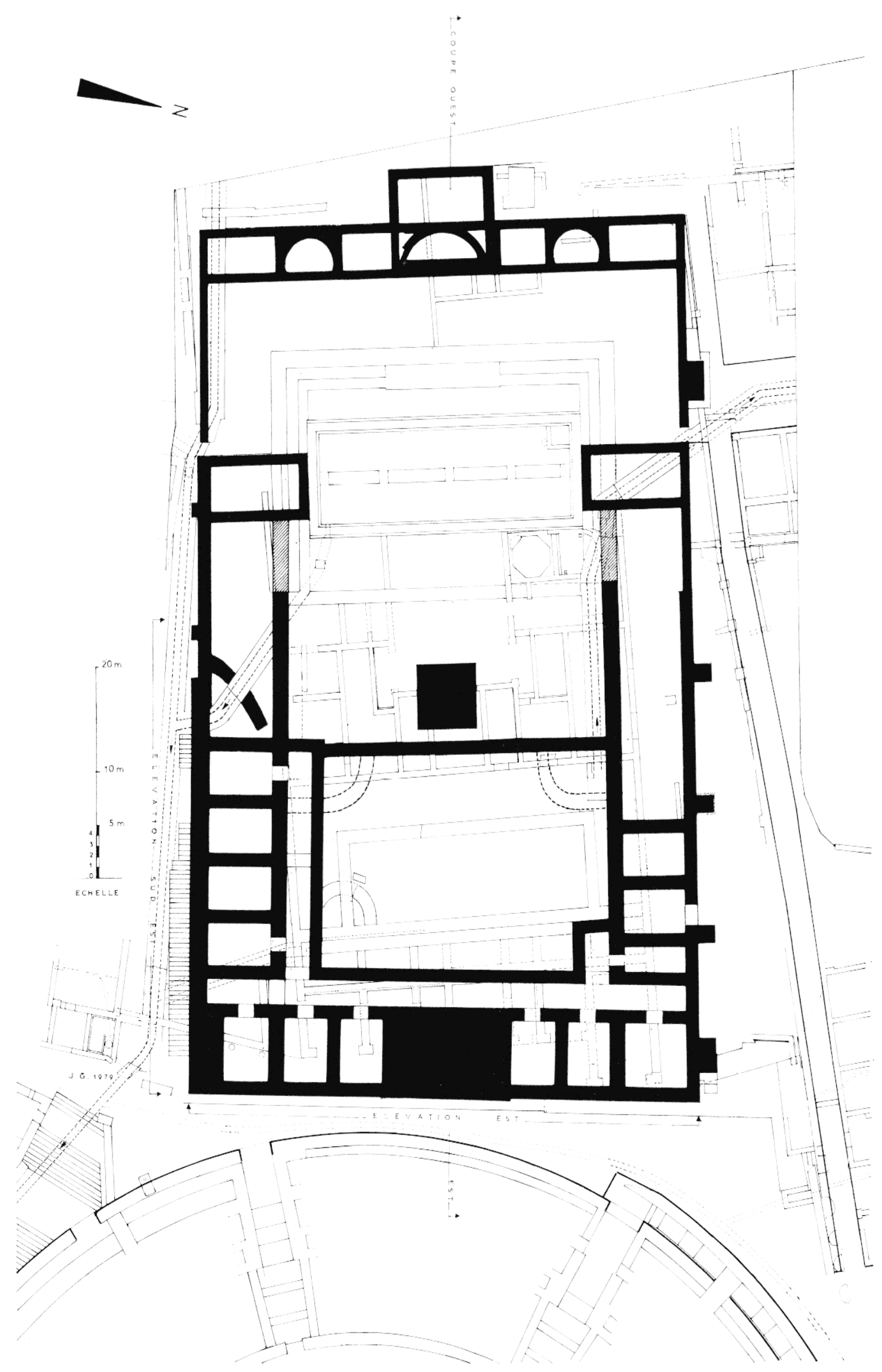

4 Les substructions du sanctuaire. 
Mais il n'en alla pas de même pour la partie orientale. Là où le sol s'abaissait rapidement vers les Minimes, le prolongement de l'édifice n'avait pu se faire que par entassement d'alvéoles constructifs qui ne manquèrent pas de s'écrouler au cours des temps. Toutefois, lors de la découverte, le mur oriental dominait encore de plusieurs mètres la rue dallée ceignant le théâtre, et, malgré les destructions de maçonneries, on put faire une restitution intégrale du plan de l'édifice.

\section{ASSIETTE DU SANCTUAIRE}

C'est un rectangle irrégulier (fig. 4) mesurant $50 \mathrm{~m}$ à l'o., $52,79 \mathrm{~m}$ à l'e., $84 \mathrm{~m}$ au $\mathrm{n}$. et $81,66 \mathrm{~m}$ au s. La réduction de la face s. est due à la préexistence du théâtre dont la courbe étrangle à $3,10 \mathrm{~m}$, la rue séparant les deux édifices; celle de la face o. à la présence d'un édifice antérieur non encore exploré ni identifié, qui se trouve tangent à l'angle s.-o. Cette forme trapézoïdale avait pour conséquence que les faces intérieures e. et o. n'étaient pas strictement sur le même axe. Mais l'ensemble était bien délimité par un mur continu ne réservant que deux étroites entrées latérales.

L'orientation longitudinale de cet enclos de $4266 \mathrm{~m}^{2}$ était un axe situé à $11^{\circ}$ au $\mathrm{n}$. de l'e. idéal. Elle fut imposée par la présence d'un édifice civil plus ancien dont les massives structures furent partiellement réemployées dans les soubassements du sanctuaire. Le terrain qui porte cet ensemble occupe, pour la moitié o., le bord du plateau de la Sarra dont l'arête fut épousée par la ruelle des Belettes, et le reste s'accrochait au rapide versant constitué par la combinaison de deux déclivités, l'une n.-s. relativement modérée, l'autre o.-e., fort raide. Ce relief s'exprime par la cotation des quatre angles : le dallage extérieur à celui du s.-e. est à 275,27 , le dallage à l'angle n.-e. à 281,10 . le bloc de l'anglc n.-o. à 291,77 , la maçonnerie de l'angle s.-o. à 293,31 , soit $18 \mathrm{~m}$ plus haut que la première cote.

Seul le bloc angulaire n.-o., en calcaire tendre, parce qu'il était placé en fondation, fut retrouvé en place. Au cours de son dégagement pour réemploi, le bloc angulaire s.-o. fut traîné au-dessus d'un égout dont la voûte s'effondra sous son poids. Retrouvé debout dans cet égout, il a été remis à sa place d'origine. La nature de ce bloc, et d'un autre trouvé près de là hors de site, montre que les parties aériennes du sanctuaire étaient d'un calcaire jurassique portlandien blanc et dur, tiré des carrières de Fay, à Peyrieu (Ain), et apporté commodément à Lugdunum par voie fluviale ${ }^{19}$. De même origine sont toutes les pierres de taille des édifices lyonnais construits à partir du milieu du $\mathrm{I}^{\mathrm{er}} \mathrm{s}$. de notre ère. Le sanctuaire fut dépouillé de ces blocs en même temps que ses voisins, théâtre et odéon.

ORDONNANCE DE L'EDIFICE

De la partie orientale ne demeurent visibles que des vestiges fortement érodés, mais qui, bien que situés très au-dessous du plan de l'édifice, peuvent permettre un essai de restitution des structures aériennes disparues. 
Large de $13,35 \mathrm{~m}$, le massif central de la face orientale débordait de quelques centimètres le vif de la façade, un peu plus au n. qu'au s. afin de ne pas mordre trop sur la rue que rétrécissait progressivement la courbe du théâtre. Dans l'autre sens, il mesurait $8,80 \mathrm{~m}$. Les quatre angles avaient été garnis de chaînages de pierres de taille, épais de $0,80 \mathrm{~m}$ à $0,97 \mathrm{~m}$, s'étalant de $1,80 \mathrm{~m}$ à $2,14 \mathrm{~m}$ sur chaque face. Les ailes qui l'encadraient étaient longues, celle du s. de $20,03 \mathrm{~m}$, celle du n. de 19,39 m. Closes sur la rue par un mur épais de 1,27 m, elles l'étaient à l'o. par un mur épais de $1,30 \mathrm{~m}$, alignė exactement sur la face intérieure du massif central. Les deux murs étaient distants de 6,02 $\mathrm{m}$ au s. et de $5,97 \mathrm{~m}$ au $\mathrm{n}$. A l'extrémité de l'aile s., où l'abaissement du sol exigeait un renfort puissant, le mur s. était épais de $3,72 \mathrm{~m}$ et possédait un chaînage angulaire épais de $1,20 \mathrm{~m}$, étalé de 4,50 m sur les deux faces. A l'extrémité n., où ce renfort était moins nécessaire, le mur ne mesurait que $1,20 \mathrm{~m}$ et le chaînage, de même épaisseur, s'étendait de $2,70 \mathrm{~m}$ seulement sur les deux faces. Il en résultait une inégalité de largeur des alvéoles. Commençant par le s., ils mesurent respectivement $4,64 \mathrm{~m}, 4,54 \mathrm{~m}$ et $4,37 \mathrm{~m}$ d'une part, de l'autre $4,53 \mathrm{~m}, 4,25 \mathrm{~m}$ et $6,34 \mathrm{~m}$. Ces chiffres sont instructifs : ils révèlent que la construction des alvéoles fut commencée par le s. et que l'aile fut divisée en trois parties approximativement égales, séparées par des murs de 1,60 m et 1,25 m. Le moment venu d'établir les alvéoles de l'aile n., sans doute utilisa-t-on d'abord les coffrages des deux derniers alvéoles du s. que séparait un mur de 1,25 m. Il restait au-delà un large vide dû à la minceur relative du mur extérieur $n$. : d'où la largeur insolite du dernier alvéole dont la voûte portait, au s., sur un mur épais de 1,58 m et marquait sur son aplomb une cassure disgracieuse.

Ces alvéoles étant couverts de voûtes, leurs extrados devaient être tous de niveau. S'ils ont été détruits, la voûte du sixième, beaucoup plus large, portait sur une génératrice placée à un niveau inférieur aux autres et qui a laissé des traces. Ainsi peut-on calculer que le plan des extrados était coté 286,80 . Le sol du sanctuaire - celui du plateau - étant, on le verra, coté 292,65 , la différence de $6 \mathrm{~m}$ suggère l'existence d'un étage intermédiaire.

Derrière l'ensemble constitué par le socle et les alvéoles, limité à l'o. par un mur de $1,23 \mathrm{~m}$, un couloir large de 2,42 $\mathrm{m}$ traverse l'édifice dans toute sa largeur. Il était accessible, à l'extrémité s., par une baie de même largeur, ouverte à plusieurs mètres au-dessus de l'escalier qui longeait la face s. du sanctuaire, escalier dont l'ordonnance n'est pas connue. Cette baie permettait de pćnćtrer par le couloir dans les alvéoles aux fins de vérification et de ventilation. Des ouvertures de $1,60 \mathrm{~m}$ sont effectivement visibles entre couloir et alvéoles, là où le mur qui les sépare, comme dans l'alvéole 3 , a conservé une hauteur suffisante pour les révéler.

Parce qu'il était pareillement en surplomb, le côté s. du sanctuaire avait, en son extrémité orientale, bénélicié des mêmes dispositions. Derrière le mur externe, réduit à $1,84 \mathrm{~m}$ d'épaisseur à partir de la baie d'accès, quatre alvéoles, profonds de $6,57 \mathrm{~m}$, mesuraient respectivement 4,08, $4,16,4,30$ et $4,30 \mathrm{~m}$. Ils étaient séparés par des murs oscillant entre 1,28 et 1,30 m d'épaisseur. Au-delà du mur qui en constituait le fond au n. épais de $1,60 \mathrm{~m}$, un couloir de $2,47 \mathrm{~m}$, limité au n. par un mur de 1,25 m, se branchait à l'équerre sur le couloir oriental et, sur $21,20 \mathrm{~m}$ de long, desservait ces quatre alvéoles. Le niveau de destruction a permis de découvrir le passage de ventilation du premier. En outre, dans le mur du troisième alvéole apparaît la génératrice de la voûte qui était ici à un niveau supérieur à celle des alvéoles de la face orientale.

A l'angle n.-e., où le sol extérieur est sensiblement surélevé, les choses se présentent plus simplement. Le mur externe n.-e. est réduit à 1,25 m d'épaisseur. Il s'aligne à $6,34 \mathrm{~m}$ du mur parallèle qui, de même épaisseur, détermine la longueur de trois alvéoles desservis par un couloir, large de $2,60 \mathrm{~m}$, long seulement de $5,17 \mathrm{~m}$, branché comme son symétrique s., sur le grand couloir transversal.

Le premier alvéole avait une largeur réduite à $2,43 \mathrm{~m}$. Son mur 0 . de médiocre apparence, truffé de briques, soutenait le mur oriental du second qui était, en fait, une salle large de $4,12 \mathrm{~m}$, formant un local de service, sans doute un logement de gardien, comme en témoignent les traces d'enduit blanc épais de $0,01 \mathrm{~m}$, visibles à la base des parois. Le sol de ce local était fortement surélevé de manière à en permettre l'accès depuis la région circonvoisine. Malheureusement, une large et profonde excavation, résultant vraisemblablement de l'extraction médiévale de moellons, 
a ruiné le mur n. là où devait exister une porte. Un troisième alvéole, simplement constructif et large de 4,12 m, était clos à l'o. par un mur aligné à $27 \mathrm{~m}$ de la face orientale de l'édifice.

Ainsi, tout le système des alvéoles et des couloirs se présentait en symétrie, moins développé au n. qu'au s. en fonction du profil du sol. Il n'en devait donc rien apparaitre dans les parties aćriennes de l'édifice, qui, à l'exception du logement de fonction, n'étaient que des substructions.

On n'en dira pas autant des murs externes du s. et du n. Au droit du premier alvéole, le mur s. est épais de 3,72 m. A partir du couloir n.-s., il se réduit à $1,84 \mathrm{~m}$ et maintient, cette largeur sur $31 \mathrm{~m}$, couvrant ainsi les quatre alvéoles de la face $\mathrm{s}$. Plus loin, l'alignement extérieur s'efface de $0,65 \mathrm{~m}$, son épaisseur étant réduite d'autant, mais il est soutenu par deux contreforts de $0,65 \mathrm{~m}$ de saillie et de $1,30 \mathrm{~m}$ et $1,34 \mathrm{~m}$ de large. Il s'interrompt a $21 \mathrm{~m}$, au droit d'une porte dont on reparlera.

A partir du couloir n.-s., le mur externe est doublé par celui qui ferme d'autre part les alvéoles. Ceux-ci dépassés vers l'o., on penserait que ce second mur n'a plus de raison de se prolonger, la pente du sol n'exigeant plus le renfort d'alvéoles. Bien au contraire, il se poursuit jusqu'à un pavillon transversal, large extérieurement de 6,20 m, intérieurement de $4,30 \mathrm{~m}$ et débordant de $2 \mathrm{~m}$ dans la cour intérieure du sanctuaire. Ainsi, les deux murs parallèles se poursuivent sur le plateau après avoir échangé lcur fonction de soutènement contre celle de support d'une aile de construction large de $9,90 \mathrm{~m}$, longue de $45,60 \mathrm{~m}$.

Le mur externe n. ne ressemble pas à celui du s. Appuyé sur un chainage angulaire plus modeste, il mesure $1,25 \mathrm{~m}$ d'épaisseur sur une longueur de $48,60 \mathrm{~m}$. Au-delà, sur $14 \mathrm{~m}$, il se réduit à $0,90 \mathrm{~m}$ par retrait intérieur, et non extérieur comme au s., jusqu'à une embrasure symétrique à celle qui fait face. Cette épaisseur, relativement faible, avait imposé la construction de six contreforts carrés de $1,70 \mathrm{~m}$ à $1,90 \mathrm{~m}$ de côté, implantés à des intervalles de 36 pieds, soit 10,60 m. En outre la largeur plus grande du sixième alvéole de la face orientale entraînant une poussée plus grande de la voûte sur un mur plus faible, le premier contrefort extérieur avait été doublé par un autre de mêmes dimensions.

A partir du couloir n.-s., à ce mur externe en répondait un second, distant de $6,34 \mathrm{~m}$, couvrant les trois locaux sur quelque $16 \mathrm{~m}$. Comme à l'aile $\mathrm{n}$., ce mur se poursuivait jusqu'à un pavillon symétrique à celui du s. Ial longueur de l'aile n. est de $47,50 \mathrm{~m}$, sa largcur de $9,15 \mathrm{~m}$. Les distorsions imposées au plan du sanctuaire par les édifices préexistants expliquent les différences signalées dans la longueur des deux ailes.

\section{PARTIES AERIENNES}

Que portaient ces substructions au niveau supéricur, celui du plateau? Projetons à ce niveau les seuls éléments n'ayant pas strictement valeur de soutènement : les alvéoles ne répondaient à rien en élévation; à plus forte raison les couloirs qui les desservaient; sculs paraissent, au niveau supérieur, les deux murs parallèles constituant la face orientale et les ailes.

Au centre de la première, le massif axial occupait une place privilégiée. La laiblesse relative de ses proportions : 13,33 sur $8,80 \mathrm{~m}$, incite à y voir une simple cella, mais commandant l'ensemble du sanctuaire. Dans un local proche de l'angle s.-e. de celui-ci fut retrouvé, hors de site, un chapiteau corinthien (fig. 5) (milieu du $\mathrm{II}^{\mathrm{e}} \mathrm{s}$. ?). Haul de $0,86 \mathrm{~m}$, il coiffait une colonne de 7,20 , portant un entablement de $1,90 \mathrm{~m}$. Compte tenu d'un podium et d'un fronton, cela pourrait constituer un édifice de $12 \mathrm{~m}$ de hauteur minimum. Ce chapiteau provenait-il de la façade de la cella ? La faible profondeur de celle-ci fait. songer à un ordre de deux colonnes in anlis, clòture très aérée permettant de voir la statue de culte de la déesse, celle dont provient la belle tête de marbre blanc d'une divinité matronale, coiffée du calathos, aux cheveux peints en rouge. Trouvée en 1967 à còté du four à 


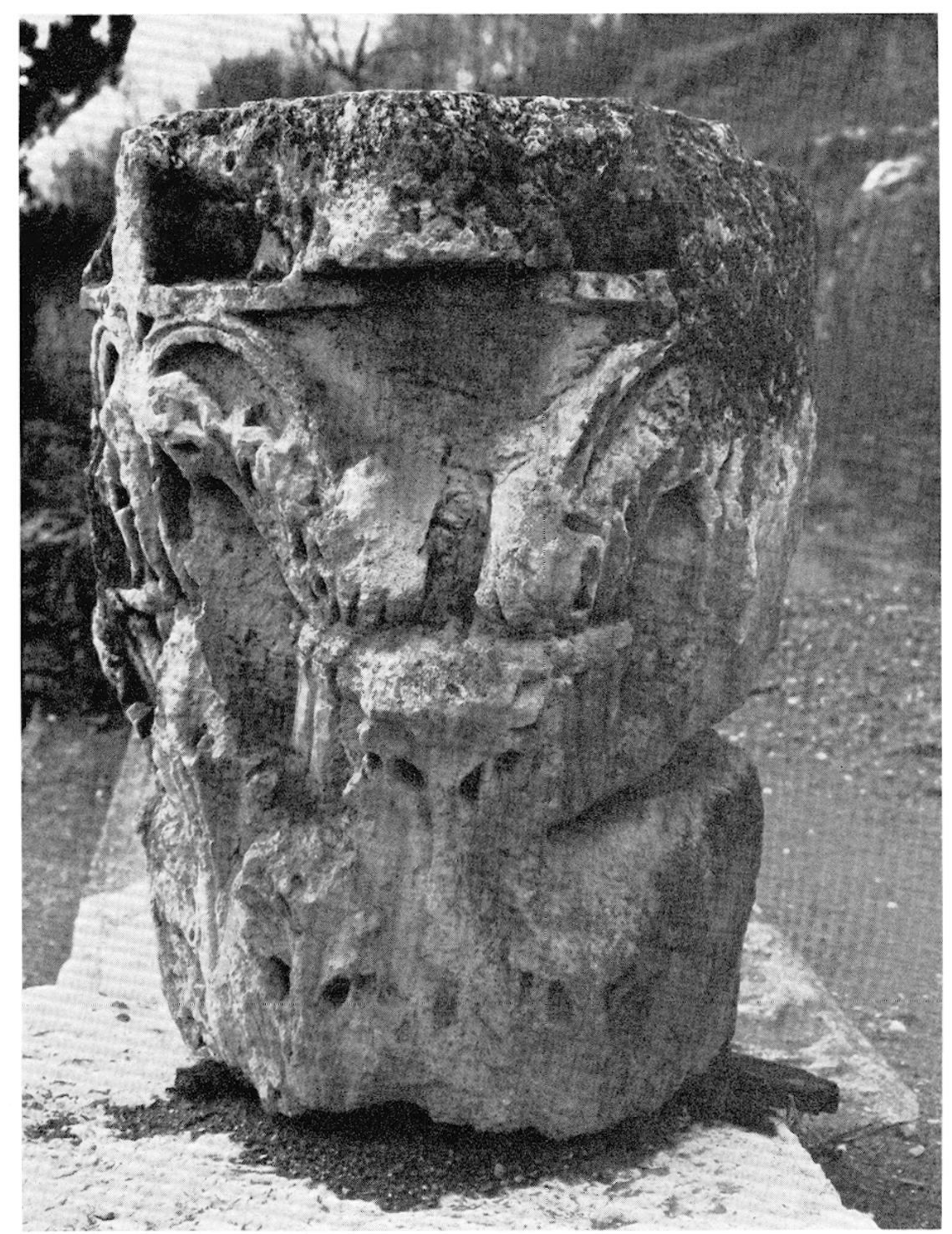

5 Chapitean du lemple.

chaux de l'odéon avec d'autres éléments pouvanl provenir de la mème statue, elle trahissait des dimensions doubles de la taille naturelle (fig. 6).

De part et d'autre de la cella s'amorçaient des constructions porlées par les deux murs parallèles et mesurant $10 \mathrm{~m}$ de façade sur une largeur de $8,50 \mathrm{~m}$. Elles retournaient à l'équerre à chaque extrémité pour se lier aux ailes lalérales, longues, au n. de $47,50 \mathrm{~m}$, au s. de $45,60 \mathrm{~m}$, el buter finalement contre les pavillons débordants. Il est impossible d'imaginer les structures aériennes correspondantes, peut-êlre des galeries. La différence de quelque $6 \mathrm{~m}$ entre l'extrados des alvéoles et le sol supérieur, augmentée de la surélévation des galeries par rapport au niveau du campus, laisse penser qu'il existait des locaux intermédiaires. Le culte de Gybèle comportait des riles secrets et nocturnes. On peut se demander si, des galeries latérales, on ne descendait pas dans des locaux situés sous l'aile orientale et la cella. 


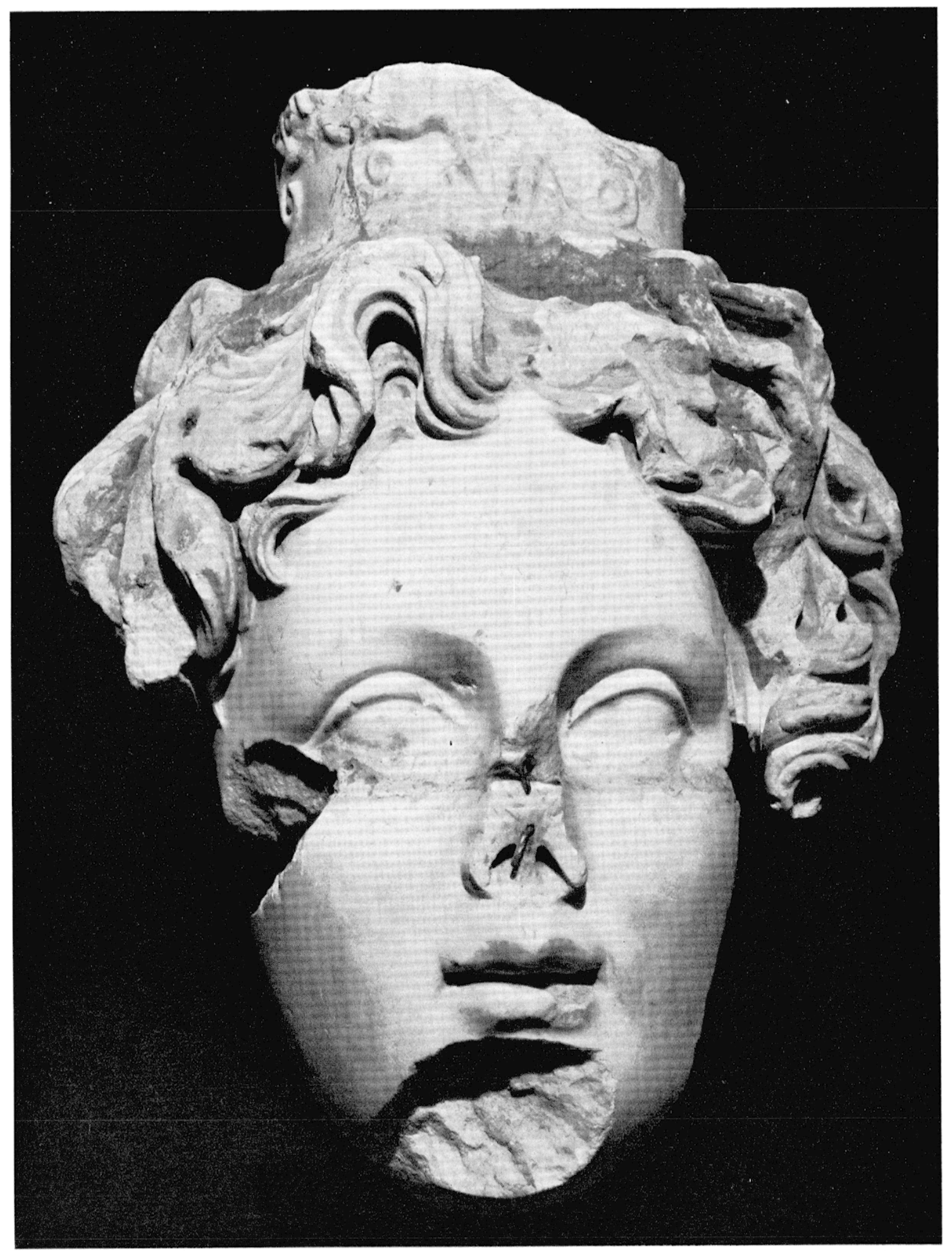

6 Tête de marbre de la statue de Cybile trouvée pris du sanchuare on 1964. 


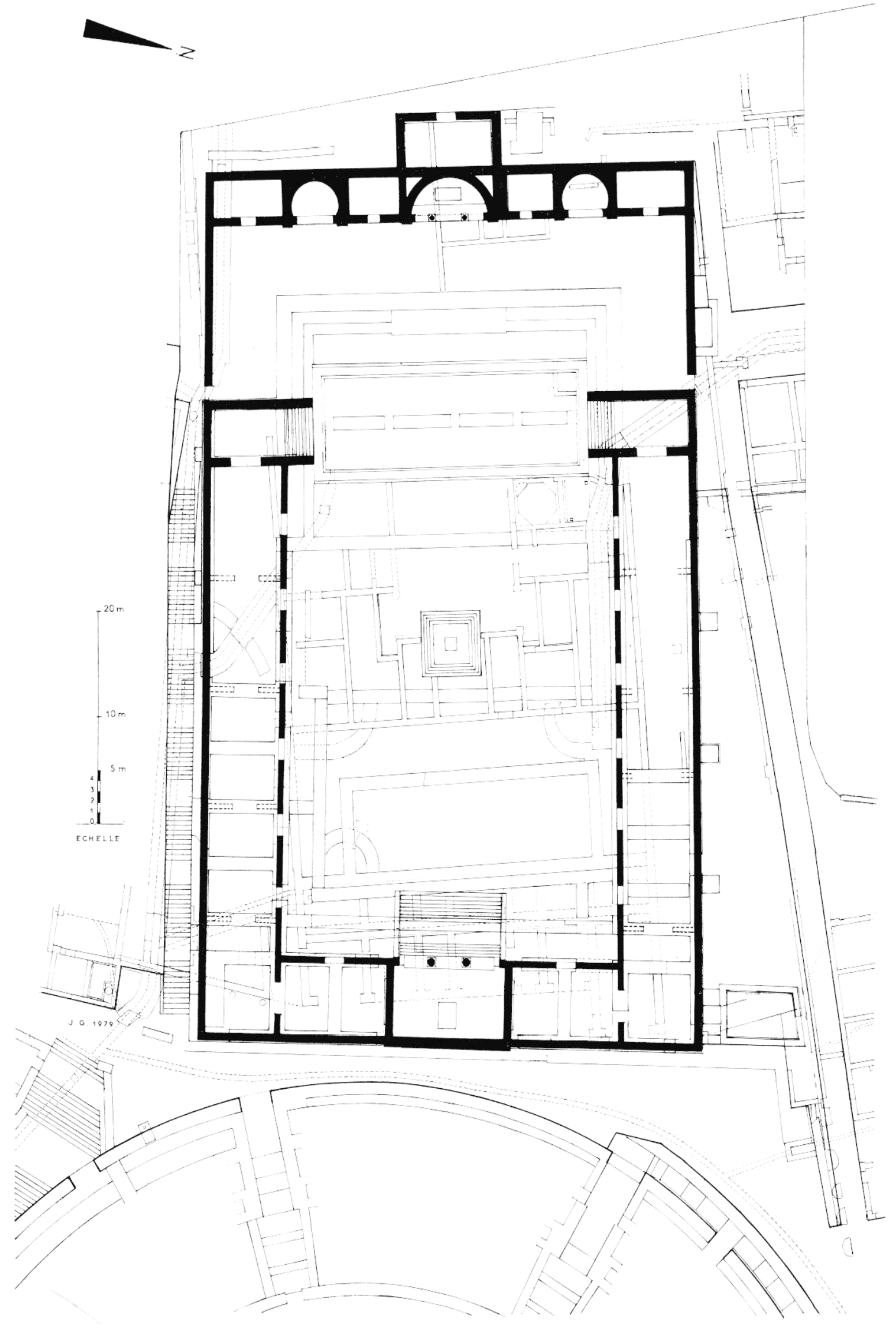

7 Essai de restitution du sanctuaire de Cybèle. 
Quant aux pavillons, ils pourraient contenir des escaliers permettant d'atteindre les galeries, la saillie ayant précisément reçu cet emmarchement. Non sans arbitraire, ce parti a été retenu pour la maquette qui a la prétention de matérialiser l'aspect du sanctuaire (fig. 7).

LE CAMPUS

L'ensemble - cella, galeries, pavillons - enveloppait une première cour, large de $33,20 \mathrm{~m}$ à l'e. et de $32,40 \mathrm{~m}$ à l'o., longue de $53,40 \mathrm{~m}$ au n. et de $52,20 \mathrm{~m}$ au s. Au centre un socle maçonné, de $6 \mathrm{~m}$ de côté, devait porter un autel dans une situation analogue à celui du sanctuaire de Cybèle à Ostie.

Le relief du sol interdisait toute communication entre cette cour et l'extérieur. On ne pouvait y accéder que par son extrémité o., largement ouverte sur une seconde cour perpendiculaire, comme la barre transversale d'un 'T sur sa hampe.

Cette cour mesurail 48,60 m sur 16,50 m et possédait en ses deux angles n.-e. et s.-e., deux portes déjà signalées au-delà des pavillons. Elles ouvraient au débouché de deux rues qui les atteignaient perpendiculairement. Celle du n., dont la largeur avait été portée à $6,50 \mathrm{~m}$, rejoignait à courte distance la rue d'Aquitaine, axe des quartiers supérieurs de la colonie. L'autre, dont seul est apparu l'angle n.-e., disparaît sous la moderne maison des Cèdres. l)es égouts utilisaient ces deux ouvertures pour franchir le mur de clòture du sanctuaire.

De la porte $n$., la principale, qui devait être assez large, rien ne demeure par le fait d'une destruction récente, mais limitée. Quant à la porte s., large de 1,25 m, elle était de niveau avec le sol extérieur. Le mur de clòture était donc réduit à $0,80 \mathrm{~m}$ d'épaisseur et les substructions en sont d'une maçonnerie soignée de granits irréguliers.

Les murs latéraux $n$. et $\mathrm{s}$. entourant cette partie du sanctuaire sont longs de $20 \mathrm{~m}$ et unis par le mur 0 . de $50 \mathrm{~m}$, les uns et les autres entièrement aveugles. Le mur s. s'aligne avec un léger retrait sur la portion orientale et le mur $n$. se réduit à $0,75 \mathrm{~m}$ en un point où les maçons furent gênés par un mur antérieur. Au surplus, le dernier contrefort de la face n. fut doublé pour une raison qui ne peut être que la fragilité de cette haute paroi.

Les angles des murs comportaient des chainages de pierres de taille. Au s., le grand bloc de "choin » en calcaire de Fay, relevé par nos soins, mesure $0,76 \mathrm{~m}$ sur $1,10 \mathrm{~m}$ et $1,90 \mathrm{~m}$ de haut. Au n. se voit encore dans la fondation, un bloc de grès jaunâtre de $0,96 \mathrm{~m}$ sur $1,17 \mathrm{~m}$ et $0,63 \mathrm{~m}$ de haut.

ORDONNANCE DE LA PARTIE OCCIDENTALE IUU SANCTUAIRE

Elle requiert une attention particulière. A $3,55 \mathrm{~m}$ en avant du mur de fond, court, sur toute la largeur, un mur, épais de $0,80 \mathrm{~m}$ aux ailes, de $0,70 \mathrm{~m}$ au centré vù il est doublé par un contre-mur de $0,85 \mathrm{~m}$. Ne constituant qu'un stylobate, il est maçonné avec négligence en schistes très irréguliers et est parvenu à un état fort dégradé. Cette largeur de 1,55 m au centre laisse supposer qu'il est celui que reconnurent les fouilleurs de 1925.

L.'espace entre les deux murs est coupé par des murs délimitant, sept loges. Dans celle du centre, large de $11,40 \mathrm{~m}$, s'encastre, en place d'honneur, une abside formée par un mur circulaire de $0,80 \mathrm{~m}$. Il s'appuie sur le mur n. san: se marier avec lui et en réduisant sa propre épaisseur à $0,20 \mathrm{~m}$. Il est tangent, à l'e. au mur de doublage. $\Lambda$ u s., le mur latéral est épais de $0,65 \mathrm{~m}$, comme celui du $\mathrm{n}$., lequel est doublé par un contre-mur dont le mortier est de couleur différente, qui porte la largeur totale à $1,45 \mathrm{~m}$. Le mur circulaire de l'abside s'amincit à $0,74 \mathrm{~m}$ au contact du mur s. et à $0,20 \mathrm{~m}$ 
au contact du mur n. La courbure de cette niche, dont la largeur maximale est de $8,60 \mathrm{~m}$ et la flèche de $2,55 \mathrm{~m}$, était donc loin d'atteindre le demi-cercle puisque son diamètre théorique serait de $9,80 \mathrm{~m}$. Le fond de l'abside est rompu, mais la brèche résulte certainement d'un fait récent, peut-être la plantation d'un arbre fruitier. On aurait pu supposer que cette niche absidiale soit postérieure à la construction du sanctuaire. Cette hypothèse n'est pas à retenir : la déviation qui affecte le mur s. tient compte de son existence.

On a vu que le mur sous-tendant l'abside avait servi de stylobale. De son voisinage proviennent une plaque de marbre blanc portant des cannelures de colonnes, et surtout l'abaque coiffant la volute d'un chapiteau corinthien qui s'orne de denticules. Selon M. Ward-Perkins, il n'existe pas de parallèle à telle décoration, et l'habitude d'orner l'abaque des chapiteaux, très rare en Italie et dans les provinces, est caractéristique de l'art gallo-romain. Ia niche était-elle confortée par deux colonnes in antis et coiffée d'un fronton ? La faible courbure de l'abside exclut l'existence d'un cul-de-four. L'entablement, et l'attique qu'il portait, se prolongeaient sans doute au sommet des locaux voisins. De part et d'autre, en effet, étaient deux salles rectangulaires, encadrées de murs de $0,80 \mathrm{~m}$, larges intérieurement, celle du s. de $5,17 \mathrm{~m}$, celle du $\mathrm{n}$. de $5,49 \mathrm{~m}$, avant d'avoir été réduite à 4,71 m par le doublement du mur déjà signalé. Celui du s. marque une oblique sensible, répondant à la déviation analogue du mur de la niche centrale.

Au-delà, deux nouvelles niches rondes, celle du n. de $4,86 \mathrm{~m}$, celle du s. de $5,10 \mathrm{~m}$, n'étaient pas formées, comme celle du centre, par un mur circulaire, mais par des massifs plaqués contre les murs latéraux de manière à ne pas dépasser $0,20 \mathrm{~m}$ à leur contact. Au s., le massif faisait mème corps avec le mur s., démontrant que la niche est bien d'origine. D'autre part, si le mur qui sous-tend les niches à l'e. ne se superpose pas à leur diamètre, le centre du cercle se situe à 0,75 m en arrière de ce mur, déterminant une niche à plan largement oulrepassé qui contraste avec la large ouverture de la niche centrale.

Aux extrémités se retrouvent deux locaux rectangulaires, celui du s. de 7,05 m de largeur, celui du n. de 7,95) m. Visiblement leurs largeurs correspondent systématiquement à celle des galeries de la première cour de manière que les trois niches soient visibles de tous les points du campus.

Ainsi, la face intérieure occidentale du sancluaire présentait un aspect mouvementé, et l'on ne manquera pas d'établir un rapprochement entre son décor à trois niches et le frons scenae d'un théâtre (fig. 8).

\section{CIRCULATION DES EAUX PLUVIALES}

La superficie du campus l'appelait à recevoir une quantité d'eaux pluviales. Le système établi pour les évacuer a été repćré au pied des ailes latérales, mais plus claircment au n.

Utilisant les soubassements de l'édifice préexistant, fut aménagée sous le sol du campus une fosse en quart de cercle de $3 \mathrm{~m}$ de diamètre, close par un mur de $1,20 \mathrm{~m}$, située dans l'angle n.-e. de la cour. On ne peut interpréter celle structure que comme le réceptacle des eaux accumulćes dans le campus, emportées ensuile à l'extérieur par un égout. Cet égout est conservé, de bout en bout, le long du mur interne de la galerie n. Sorlant de la fosse, il longeait cette galerie en direction de l'o. sur un parcours de $20 \mathrm{~m}$, au long duquel, sauf dans les 3 derniers $\mathrm{m}$, il est réduit à son seul radier. Puis il traversait en baïonnette le mur de la galerie. Intégralement conservé en ce point, il est large exlérieurement de $1,70 \mathrm{~m}$ el son radier est fait de deux lils superposés de trois briques posées à plat, de $0,3,3 \mathrm{~m}$ sur $0,45 \mathrm{~m}$. Sa hauteur est de $1,35 \mathrm{~m}$ a $1,55 \mathrm{~m}$ sous clef. I.es piédroits sont hauts de $1,02 \mathrm{~m}$ à $1,15 \mathrm{~m}$, et la largeur intérieure oscille entre $0,70 \mathrm{~m}$ et $0,75 \mathrm{~m}$. La voǹte, au profil extérieur rectangulaire, est de schistes, à l'exclusion de briques, ainsi que les piédroils. Long de $28 \mathrm{~m}$ au total, cet égout se déversait finalement dans un autre, plus ancien, qu'il coupait transversalement, dont 


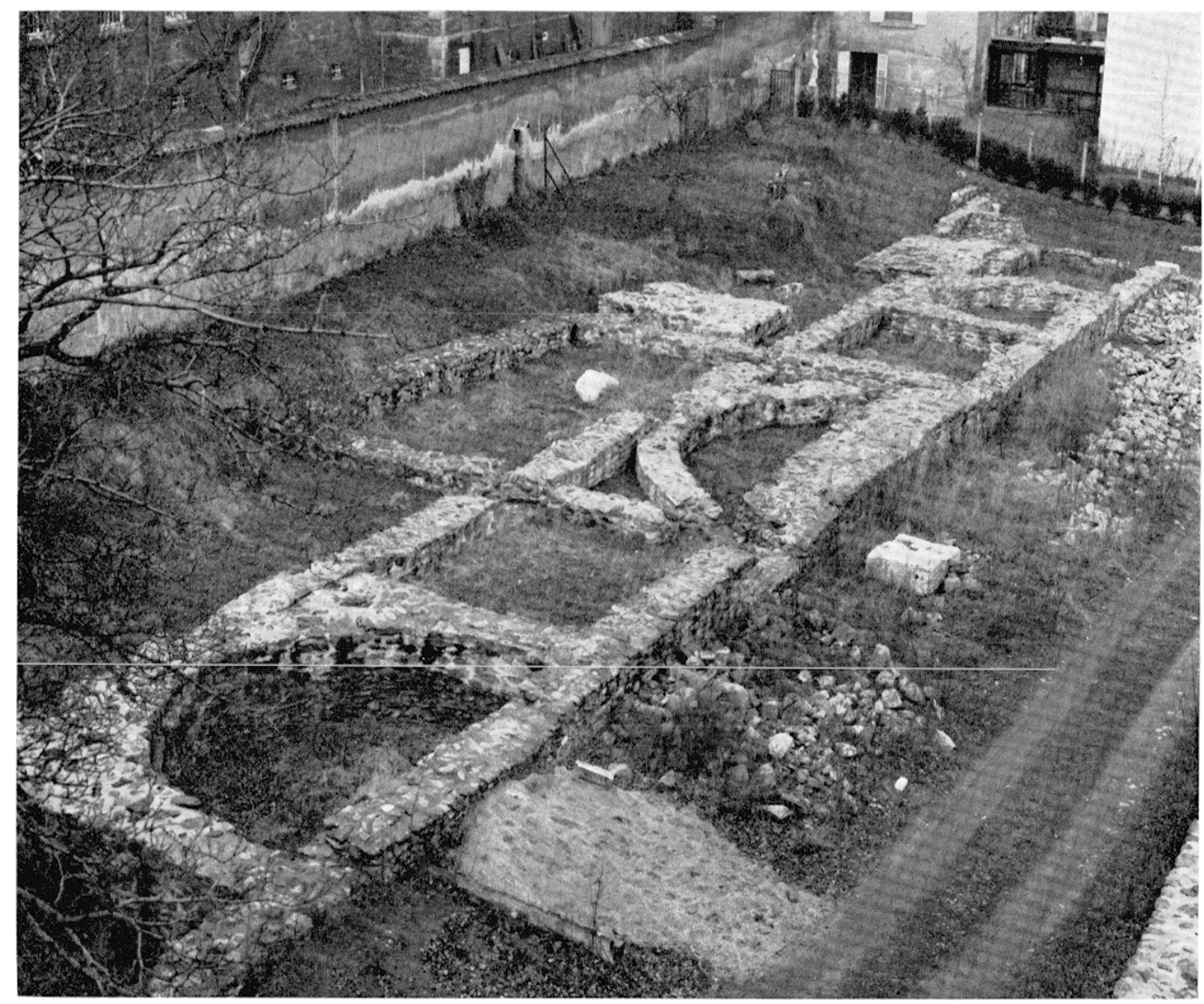

* La decor des niches fermant à l'o. le campus de cybile.

le radier élait de $0,50 \mathrm{~m}$ inférieur au précédent, el qui rejoignait finalement celui de la rue d'Aquitaine. On le décrira plus loin.

Le dispositif qui existail symétriquement au pied de la galerie s. a laissé peu de vestiges. Assez cependant pour que son existence soil assurée. Il prenait naissance dans une fosse en quartde-rond, comme la précédente élablie dans les soubassements de l'édifice antérieur. C'est d'ailleurs la restauration de cette fosse qui a fait apparaître un fragment de fresque étudié plus loin. De l'égout lui-mème, un élément de piédroil encore coiffé de la base d'une voûte est apparu à la place attendue. Il se déversait, en inversant la course de ses eaux, dans un égout plus ancien qui, lui-même, rejoignait, un collecteur traversant partiellement le sanctuaire el largement remanié lors de la construction de celui-ci.

Ce collecteur, qui mérite ce titre parce qu'il mesure $92 \mathrm{~m}$ aux abords du sanctuaire et se prolonge encore de $150 \mathrm{~m}$ à travers le chantier archéologique, a subi, au cours des temps, de profonds remaniements dans sa structure el son tracé. Actuellement, il sort du clos du Carmel, mitoyen à l'o. à l'ancienne vigne Bourgeal. I)ans le très courl secteur qui le sépare du sanctuaire, son radier est de briques posies a plat. Au ronlant da sancluaire. il marque un léger coude sous un regard carré de 0,75) $\mathrm{m}$ de roblé. A son passige sous le mur du sincluaire. l'égout mesure 0,7:) m de large, 1,90 m de hauteur a l'extrados el 1,60 m sous la clef. Ilauteur illusoire : en son élat premier, l'égout possédait un radier de briques haules de $0,31 \mathrm{~m}$, longues de $0,4: 3 \mathrm{~m}$, épaisses de $0,0 \% 3 \mathrm{~m}$, posées de chant, en 
arêtes de poisson, et débordant sous les piédroits. La largeur totale du massif est de 1,80 m. Les piédroits sont de moellons de granit avec deux rangées de briques dans le milieu. La voûte est de longs schistes noirs sans briques.

Le mur d'enceinte du sanctuaire dépassé, l'égout en longe le mur s. qu'il franchira obliquement sous la porte latérale. Ici où le radier de briques est conservé, la hauteur intérieure de l'égout est de $1,29 \mathrm{~m}$. Cette portion a visiblement été reconstruite lors de l'érection du sanctuaire. A la sortie de celui-ci existe un second regard, en aval duquel l'égout longe extérieurement en forte pente le mur s. en s'en éloignant progressivement. Haut maintenant de 1,25 m intérieurement, il a des piédroits de granit dont celui du s. montre en son milieu trois lits de fragments de briques formant une arase de $0,20 \mathrm{~m}$. Aucune brique ne parait dans la voûte de schistes. Au droit de l'angle s.-e. du sanctuaire, l'égout marque un coude au s. et plonge pour déboucher dans celui de la rue, qui longe la face e. de l'édifice, s'enfonģant avec lui sous l'escalier monumental du théâtre. En sa partie terminale, il mesure $0,77 \mathrm{~m}$ de large, $1,24 \mathrm{~m}$ de haut, plus $0,31 \mathrm{~m}$ correspondant à un radier de briques de chant qui, exploitées, ont laissé de profondes encoches sous les piédroits. Ceux-ci, épais de $0,80 \mathrm{~m}$, sont de granits coupés à mi-hauteur sur les deux côtés par de triples arases de briques. A l'inverse de ce qui a été constaté dans la partie haute, la voûte de schistes montre deux doubles files de briques de part et d'autre de la clef.

\section{DONNEES TECINIQUES}

I.es soubassements du sanctuaire sont de maçonneries en moellons de granit plus régulier qu'il n'est habituel dans les édifices lyonnais. Ils sont disposés en lits continus, de hauteur variable : $0,115 \mathrm{~m}$ en moyenne. Les joints sont repris au fer, en lignes horizontales continues, mais brisées dans les intervalles verticaux des moellons, donnant aux murs l'aspect d'une construction en petit appareil.

Dans la partie méridionale, où les murs sont plus élevés, se voient de triples arases, hautes de $0,21 \mathrm{~m}$, en briques de $0,43 \mathrm{~m}$ sur $0,31 \mathrm{~m}$ et $0,055 \mathrm{~m}$ d'épaisseur, présentant au vif du mur leur côté de $0,31 \mathrm{~m}$. Au-dessus des arases paraissent, de place en place, des trous de boulins.

Ces arases ne sont pas utilisées de façon systématique. Le socle de la cella en montre sur les faces n. et s. seulement. Le mur fermant les alvéoles en livre sur les deux faces, le mur n. n'en possède pas, mais le mur s. en est largement, fourni : d'abord trois lits de part et d'autre de la baie d'accès aux couloirs, progressivement moins étalés en largeur en se superposant; à un niveau supérieur, deux autres arases devaient être continues et couper toute l'épaisseur de la maçonnerie.

Le couloir n.-s. montre deux lits en ses parties hautes, mais pas à la génératrice de la voûte. Ces lits, à partir du s. de la face e, apparaissent entre le 1 er et le $2^{2}$ alvéole, entre le $2^{\mathrm{e}}$ et le $3^{\mathrm{e}}$, entre les $4 \mathrm{e}, 5^{\mathrm{e}}$ et $6^{\mathrm{e}}$, et sur la partie du socle de la cella, côté du 4 e alvéole. Le dernier alvéole n'en possède, ni dans son mur, ni à la génératrice de la voûte. Derrière le mur s. les deux premiers alvéoles n'en ont pas, mais dans ce qui subsiste de la voûle coiffant le dernier, paraît une double rangée constituant non une arase murale, mais des claveaux de voûte. Énfin, la baie qui dessert l'étroit alvéole de la face $\mathrm{n}$. livre une triple arase au sommet du piédroit et, immédiatement, au-dessus, une quadruple rangée de claveaux soulignant le départ d'une voûte dont le reste a disparu.

Le mur s. de la galerie n. révèle encore, de place en place, des coups de sabre correspondant à des stades de la construction. L'un s'aligne avec la face o. du mur o. de ce que l'on définira comme une basilique. Un autre, à $16,20 \mathrm{~m}$ plus à l'o., là où l'égout de la 
galerie s'engage sous celle-ci. On peut mème, en ce point, constater que le mur de la galerie, tout en granit, se superpose exactement à celui du réservoir sous-jacent, tout en schistes. Telle coïncidence illustre le fait que l'orientation du sanctuaire résulte bien de la réutilisation de substructions antérieures.

Un autre exemple d'adaptation à des substructions préexistantes, ici celles de l'édilice à plan basilical, est fourni par une observation faite dans le sous-sol du sanctuaire. A l'e. du socle situé au centre du campus, accrochée à l'extrémité du couloir desservant les quatres alvéoles s., s'amorçait une série de petits murs discontinus, épais de 1,30 m, grossièrement maçonnés, coincés entre les murs des salles de l'édifice maintenant arasés. Ces murets marquent l'arête sommitale de la forte pente du sol naturel. Il est évident qu'ils dépendent de l'ordonnance du sanctuaire, mais avec le seul dessein de soutenir le terrain. En certains points, ils ne sont plus actuellement visibles, mais les fouilles les ont révélés. De la même campagne, avec la mème destination de soutènement, est le mur courbe, épais de $1,20 \mathrm{~m}$, visible sous la galerie s. et destiné à soutenir le terrain en pente rapide vers le s.-e.

A une époque sans doute relativement tardive, au centre du mur occidental et à l'extérieur de celui-ci, fut adossé un local rectangulaire clos par un mur de médiocre texture, oscillant entre $0,90 \mathrm{~m}$ et $0,95 \mathrm{~m}$ d'épaisseur, dont les faces latérales ne coïncident que très approximativement avec le prolongement des murs latéraux de l'abside axiale. Ce local mesure extérieurement $5,10 \mathrm{~m}$ en saillie et $10,85 \mathrm{~m}$ de large, intérieurement $4,20 \mathrm{~m}$ et $8,95 \mathrm{~m}$. Comme il ne paraît pas avoir été directement en relation avec le sanctuaire, on ne peut imaginer sa destination. Au cours des sondages de 1966, alors que peu de choses en avaient été vues, on avait songé à y trouver la sole d'un escalier d'accès à une entrée monumentale. Les fouilles exhaustives ont rendu caduque cette hypothèse dont rien n'est à retenir. S'agit-il simplement d'un logement de gardien?

Au premier coup d'œil sur le plan du sanctuaire, et plus encore sur la maquette qui en a èté proposée, apparaît le trait majeur du culte de Cybèle. Il trahit une religion à mystère dont les rites assemblaient tous les initiés sur le campus : on dirait plus justement le temenos. Il ne s'agit pas d'une religion aristocratique dans laquelle le seul pontife et ses assistants pénètrent dans le temple de la divinité pour y pratiquer des rites dont le bénéfice n'intéresse que les ingénus issus des gentes patriciennes. Culte de salut, celui de Cybèle concerne tous les initiés, et les dimensions mêmes du sanctuaire lyonnais témoignent de leur importance numérique. Il n'est pas indifférent qu'elles égalent celles du sanctuaire de Ciybèle à Ostie qui pouvait passer pour la métropole occidentale du culte de la Mère des bieux ${ }^{20}$.

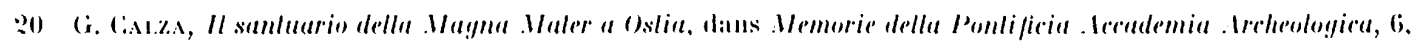

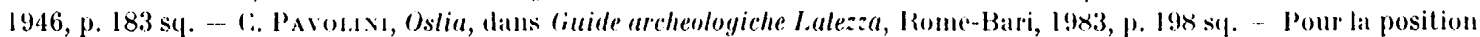
du temple par maport a son téménos, et la répartition des cons/ructions ammexes, voir F. Rakob, Das Quellenheilighum in Zaghouan und die römische Wasserleilung nach Karthago, dins Römische Milleilangen, 81, 1974, p. 81 sif. et fig. 40. 


\section{LE RÉSERVOIR TERMINAL DE L'AQUEdUC: DU GIER ${ }^{21}$}

\section{ILE PLAN DE L'ÉDIFICE (fig. 9)}

L'érection du sanctuaire implique la démolition d'un édifice à destination purement civile, dont, on l'a vu, l'orientation détermine la sienne par réutilisation d'une partie des substructions.

Cet édifice occupait un lieu où le sol naturel n'était pas encore affecté par la pente du plateau. Il est, à quelques mètres près, le point le plus élevé de la colline.

Long de $35,40 \mathrm{~m}$ du $\mathrm{n}$. au s., large de $23,90 \mathrm{~m}$, cet édifice livre un plan cohérent, bien que les constructeurs ne l'aient pas intégralement suivi, ayant fait économie en réutilisant, eux aussi, certains murs antéricurs. Réduit aux structures incluses dans le sol après arasement des murs qui eussent émergé du plan du campus de Cybèle, partiellement remblayé, il n'en a pas moins conservé un aspect imposant.

Il comportait essenticllement une citerne centrale rectangulaire, longue intérieurement de $25,95 \mathrm{~m}$ à l'o. et $26,24 \mathrm{~m}$ à l'e., large au $\mathrm{n}$. de $8,66 \mathrm{~m}$, au s. de $8,60 \mathrm{~m}$. Le radier était coté 288,67 au n. el 287,49 à l'angle s.-e., devant le trou de vidange.

Sur les faces $\mathrm{n}$. et s., le mur, épais de $0,92 \mathrm{~m}$, était renforcé intérieurement par un épaississement, de $0,25 \mathrm{~m}$, terminé au sommet par une recoupe en chanfrein très accusé, supérieure de $1,18 \mathrm{~m}$ au radier au n. et de $1,38 \mathrm{~m}$ au s., cotée partout 289,85 . Les murs e. el o., épais de 0,72 à $0,74 \mathrm{~m}$, élaient renforcés de mème manière. La citerne était coupée en son axe longitudinal par un mur épais de $1,24 \mathrm{~m}$ dans lequel ouvraient cinq baies voûlées, hautes de $1,90 \mathrm{~m}$, larges de $0,89 \mathrm{~m}$ à $0,95 \mathrm{~m}$, dont une à chaque extrémité. Elles mettaient en communication deux salles jumelles de $3,65 \mathrm{~m}$ à $3,71 \mathrm{~m}$ de largeur.

Dcux voûtes, retombant d'une part sur le mur axial, de l'autre sur les murs à chanfrein, présentaient un rayon de $1,95 \mathrm{~m}$, ce qui, compte tenu de l'épaisseur de la clef de $0,75 \mathrm{~m}$, porlait l'extrados à la cote approchée de 292,55 . S'il ne reste que la base de ces voûtes, un large pan, tombè au fond de la citerne, en conserve le témoignage.

Sols, murs et voùtes étaient enduits d'une couche de mortier à tuileaux épaisse de $0,02 \mathrm{~m}$, avec; moraines angulaires tant dans les sols que les murs et les baies. Le fait que les voûtes aient été pareillement protégées implique des conséquences sur lesquelles on reviendra. Notons la présence, dans les voûtes, de doubles arases de legulae, préalablement dépouillées de leurs rebords. Elles se distinguent des briques par leurs dimensions plus grandes et leur épaisseur moindre.

Extérieurement, les murs e. et o., et eux sculs, étaient garnis d'un voile isolant de $0,27 \mathrm{~m}$ d'épaisseur, constitué par une chaux très compacte enrobant des éclats siliceux el servant à protéger des infiltrations les eaux rassemblées dans la citerne. L'examen révélera la nécessité de cette protection.

En effet, la citerne étail inscrite dans un rectangle extérieur complexe. Sauf à l'e., ce dernier est constitué par un double mur, l'intérieur de $0,95 \mathrm{~m}$, l'exlérieur de 1,55 à 1,6 ' $\mathrm{m}$, séparés par un vide de 1,05 à $1,10 \mathrm{~m}$, empli de terre vierge, le lout épais de $3,60 \mathrm{~m}$.

Les doubles murs n. et s. sont au contact de la citerne. En revanche, les murs e. et o. en étaient séparés par un vide empli de terre d'apport dépourvue de tout fragment archéologique. La présence de cette masse imposait de protéger les eaux de la citerne de toute pollution provoquée par les infiltrations de la pluie. l'où l'existence du voile siliceux. On verra plus loin à quelle nécessité

21 A. Acmx, Le réservoir terminal de l'aquedue du Gier à L.yon, dans Actes des. Jorrnees t'éludes sur les aqueducs romains, lyon, $26-28$ mai 1977 , p. 13-18. 


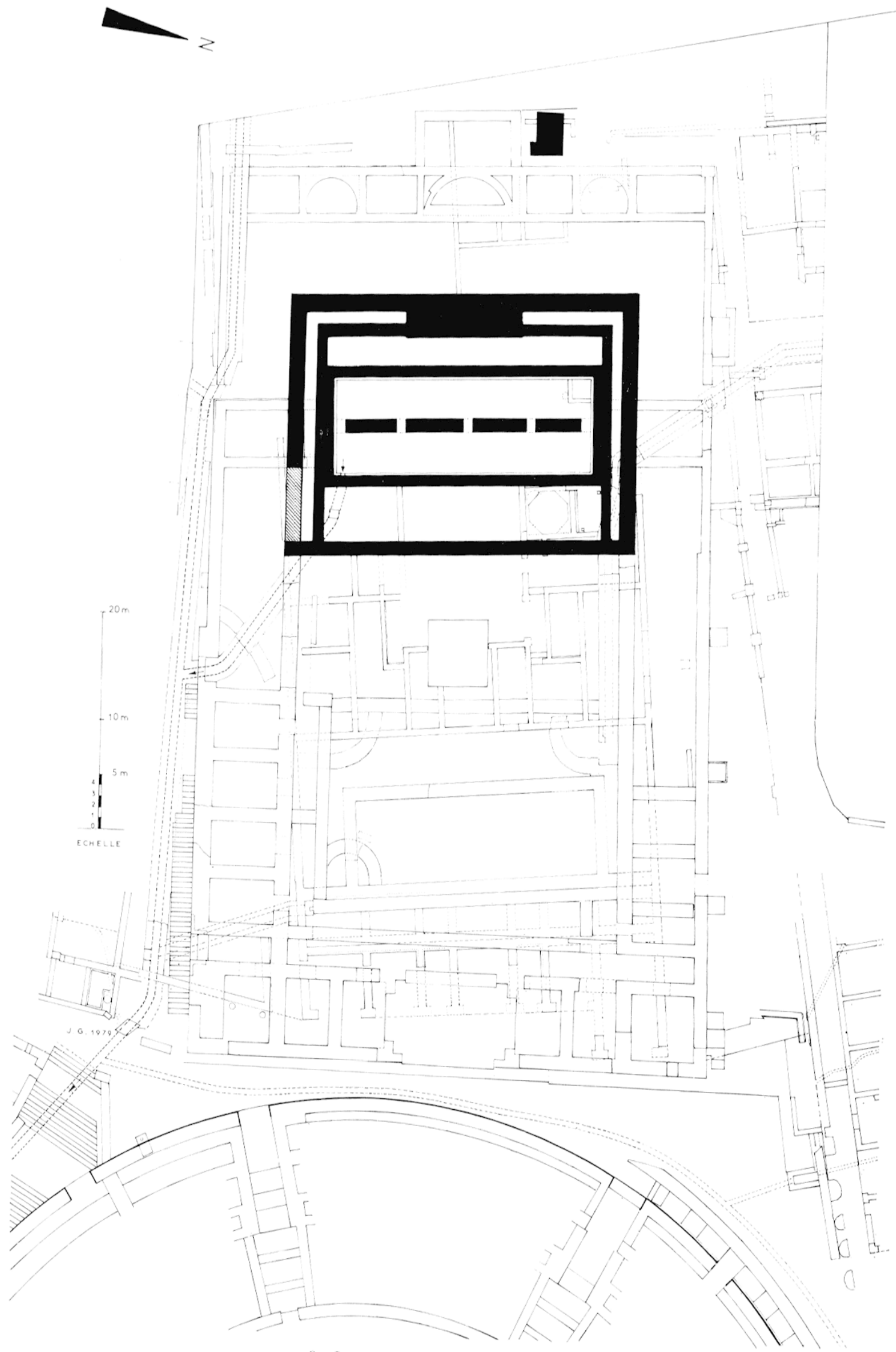

9 La cilerne de l'apuedur: du Gier. 
répondait semblable accumulation de remblai. Les deux masses latérales de ce remblai étaient contenues par des murs de dispositions différentes. A l'e., un simple mur de schistes grossièrement maçonnés, épais de $1,25 \mathrm{~m}$, retenant une masse de remblai, large de $5,10 \mathrm{~m}$. A l'o., où la largeur du remblai n'est que de $2,60 \mathrm{~m}$, il était contrebuté par un double mur semblable à ceux du n. et du s., à de menues différences près : mur interne de $0,95 \mathrm{~m}$, externe de $1,55 \mathrm{~m}$, vide intermédiaire de $1,10 \mathrm{~m}$. $\Lambda \mathrm{u}$ total 3,60 m. Dans la partie centrale, sur une largeur de $11,80 \mathrm{~m}$, le vide intermédiaire était remplacé par une maçonnerie compacte, épaisse de $4 \mathrm{~m}$, débordant à l'e. de quelques centimètres.

A ce plan préétabli furent apportées, en cours de construction, quelques modifications. Ainsi, la portion e. du mur extérieur s. fut constituée par un mur antérieur, malgré sa sensible obliquité. Mais, bien appareillé et soigneusement maçonné, le mur ancien était parfaitement efficace. Il est possible que la portion symétrique du mur n. ait été semblablement escamotée, mais on est ici au point le plus profondément dégradé de tout l'ensemble. Si l'utilisation d'un mur antérieur n'est en ce point pas démontrée, la rigoureuse coïncidence des deux murs extérieurs de la citerne avec les deux murs extérieurs de l'ensemble préexistant est un argument à ne pas négliger.

Semblable citerne exige la possibilité de nettoyage et, a fortiori, de vidange. De l'angle s.-e., au point le plus bas du radier, part un égout. Ayant traversé le mur par une anfractuosité qui a souffert de l'arrachage de la tuyauterie de plomb incluse dans la maçonnerie, l'égout s'amorce en direction du s.-e. en marquant d'abord une légère courbure. Long de $23 \mathrm{~m}$, l'ouvrage a été conservé sur toute sa longueur et, sauf sur les 5 derniers mètres, avec sa voûte. Dans un massif à profil rectangulaire, large de $1,60 \mathrm{~m}$, il mesure intérieurement $0,82 \mathrm{~m}$ de large et $1,55 \mathrm{~m}$ de haut. La voûte, dont la clef est épaisse de $0,40 \mathrm{~m}$, est légèrement surbaissée et garde les traces de son coffrage. Les murs sont de schistes à joints béants mais, sur $0,50 \mathrm{~m}$ dans la partie basse, ces joints sont garnis d'une couche de mortier à tuileaux. Aucune brique ne paraît dans la maçonnerie.

En amont, à $2 \mathrm{~m}$ du mur de la citerne, un regard maçonné de $0,72 \mathrm{~m}$ sur $0,82 \mathrm{~m}$ avait dû recevoir une vanne permettant la vidange de la citerne. A son extrémité aval, l'égout se coude vers le s. pour rejoindre le grand collecteur dont il se trouve séparé par le mur, chronologiquement plus tardif, du sanctuaire. Ce mur, de 0,62 d'épaisseur en ce point, est traversé par un petit drain permettant de libérer les eaux qui, après la construction du sanctuaire et la désaffectation de la citerne, continuèrent à se rassembler encore dans l'égout.

\section{CIRCULATION DES EAUX DANS LA CITERNE}

Cotée 288,67 au radier, la citerne ne pouvait être alimentée que par l'aqueduc du Gier dont la dernière pile subsistant s'érige dans la partie terminale de la rue Roger-Radisson, à moins de $250 \mathrm{~m}$ à l'o. du réservoir dont elle est séparée par des terrains où des fouilles ne peuvent être actuellement envisagées. Il demeure que cette pile se termine par une déviation braquée directement sur le réservoir, mais sans laisser deviner le mode de jonction : siphon en conduite forcée sous tuyaux de plomb ou file d'arcades dont rien ne subsisterait en élévation. En faveur de la première hypothèse est l'existence, derrière le mur o. du sanctuaire, d'un massif maçonné de $3 \mathrm{~m}$ sur $4 \mathrm{~m}$. Il ne peut être la sole d'une pile qui n'eût pas dépassé $2 \mathrm{~m}$ sur $2 \mathrm{~m}$. Or on se trouve là à $20 \mathrm{~m}$ du réservoir sans qu'apparaisse entre les deux la trace d'une pile intermédiaire. On cn vient à supposer que ce massif était la base d'un réservoir de chasse d'où sortaient des tuyaux de plomb. La proximité du réservoir 
terminal n'impliquerait alors qu'une perte de charge peu appréciable. Le niveau des caux. coté 300, 14 rue Roger-Radisson, voisinerait 300 sur l'emplacement du réservoir terminal.

Ainsi existait-il, entre le radier de l'aqueduc et celui du réservoir, une différence de $11,33 \mathrm{~m}$, à laquelle on ajoutera la hauteur des eaux dans le canal aqueduc: au total $12 \mathrm{~m}$ environ. L'extrados des voûtes jumelles cotait, on s'en souvient, 292,55. On doit done, admettre que, par-dessus, existait une masse liquide d'une hauteur minimale de $7,50 \mathrm{~m}$.

Impossible de mettre en doute la présence d'un étage supérieur à la citerne. On se souvient que la voûte de l'étage inférieur était recouverte d'une épaisse couche de mortier à tuileaux, ainsi que le sol de l'extrados tel qu'on le voit sur le fragment précipité dans le fond de la citerne.

En ce qui concerne l'étage inférieur, entièrement enterré, la pression des eaux sur les parois était naturellement contrebalancée par la masse du sol. Il en allait autrement pour la partie aérienne. Nul besoin de chercher ailleurs la signification des masses de terres rapportées qui contrebutaient les murs latéraux e. et o. On comprend également que les forces étaient moindres contre les parois n. et s., constituées cependant par une masse de $4,50 \mathrm{~m}$ de maçonneries et de terres, celles-ci conférant sans doute à l'ensemble une sorte d'élasticité.

Dès lors l'examen des vestiges et leur confrontation avec ceux d'édifices analogues permettent d'imaginer les dispositions adoptées pour la circulation des eaux : aboutissant dans la nef supérieure o., elles passaient par des ouvertures à travers la voûte dans la nef inférieure o. Les cinq baies les répartissaient ensuite dans la nef voisine où elles remontaient ensuite dans la nef supéricure e., laquelle était entièrement isolée de la première. Cé passage permettait la décantation des eaux, et il ne restait plus qu'à en assurer la distribution dans la ville par un système dont les données nous échappent totalement parce qu'il se situait à un niveau dont rien n'est demeuré après la construction du sanctuaire.

Germain de Montauzan précise que l'aqueduc du Gier apportait quotidiennement à Fourvière $24000 \mathrm{~m}^{3}$ d'eau. Connaissant les dimensions de la citerne terminale, il restait à déterminer comment cette masse d'eau circulait dans celle-ci et, plus particulièrement, quelle en était la capacité. M. L. Parizot a eu le mérite de faire ce calcul à mon intention : compte tenu de la hauteur d'eau dans les quatre chambres, après déduction des voûtes des chambres inférieures et des moraines et adjonction du vide des cinq baies, la capacité de la citerne était de $2008 \mathrm{~m}^{3}$ avec une incertitude de $5 \%$. Or, le débit de l'aqueduc du Gier a été estimé, au niveau des siphons de Soucieu-en-Jarrest, à $255 \mathrm{l} / \mathrm{s}$ dans le cas maximal, mais ce débit se situait plus généralement aux alentours de $200 \mathrm{l} / \mathrm{s}$, voire en été $150 \mathrm{l} / \mathrm{s}$. Il en résulte que le séjour de l'eau dans le réservoir était, dans le cas maximal, de $2 \mathrm{~h} 13 \mathrm{mn} 20 \mathrm{~s}$, dans le cas moyen de $2 \mathrm{~h} 46 \mathrm{mn} 40 \mathrm{~s}$ et dans le cas minimal de $3 \mathrm{~h} 42 \mathrm{mn} 13 \mathrm{~s}$. Ces temps peuvent paraitre assez faibles pour le dépôt du limon le plus fin. Il est vrai que le principe même de ce réservoir, obliger l'eau calme à remonter, accélérait la décantation. La troisième chambre, sans agitation, permettait déjà la précipitation des fines particules. I a quatrième parachevait l'opération. Enfin, on rappellera qu'un bassin de décantation, existant à la Martinière, point de départ de l'aqueduc, enlevait déjà à l'eau la plus grande partie des matières en suspension. 


\section{DISTRIBUTION IDES EAUX APRES LA DISPARITION DE LA GITERNE}

Construite aux alentours de 120 de notre ère, la citerne fut désaffectée aux alentours de 160. Sa démolition pose la question de la distribution des eaux de l'aqueduc après sa disparition. Nous avons le moyen d'y répondre et de confirmer du même coup, par analogie, l'analyse proposée plus haut de la circulation des eaux dans la citerne.

A $300 \mathrm{~m}$ au n.-e. du réservoir, à courte distance de la place de Fourvière, des travaux de voiric ont révélé, en novembre 1954, un système analogue à celui qui a été décrit : deux salles jumelles étaient encore coiffées par la partic basse d'un étage supérieur.

Le plan est un reclangle dont un còté court est coupé en biseau. Entre des murs épais de $0,90 \mathrm{~m}$, la partie inférieure mesure $3,60 \mathrm{~m}$ de large, $7,36 \mathrm{~m}$ de long d'un còté et $5,94 \mathrm{~m}$ de l'autre. Chaque salle est large de $1,50 \mathrm{~m}$, le mur médian est épais de $0,63 \mathrm{~m}$. Un passage voûté marque le centre de celui-ci, large de $1,50 \mathrm{~m}$, haut de $1,60 \mathrm{~m}$ sous voûte. La hauleur des salles est de $2,90 \mathrm{~m}$ et les pićdroits mesurent $2 \mathrm{~m}$. Au pied des murs court une moraine de $0,15 \mathrm{~m}$. La ruplure des voûtes a révélé une arase de deux rangs de briques à $0,30 \mathrm{~m}$ au-dessus de la génératrice et une autre de cinq à la clef. Par-dessus, un lil de galets portait un sol bétonné, celui des salles supérieures. En bout de celles-ci, à travers la voûte, existail un orifice, dans l'une de section circulaire (diam. : $0,20 \mathrm{~m}$ ), dans l'autre, de section carrée (còté : $0,45 \mathrm{~m}$ ). Malheureusement, l'extrados des salles inférieures était trop près du sol moderne pour qu'il soit demeuré de l'étage supérieur autre chose que la base du mur médian. Mais l'existence de cet étage est assurée, el l'on a observé que les salles basses étaient. enduites de mortier à tuileaux, non seulement sur les murs, mais aussi sur les parois des voûtes. Ces salles élaient donc immergées et les eaux circulaient entre les deux élages par les orifices des voûtes. $\Lambda u$ surplus elles étaient également en relation directe l'une avec l'autre. De proportions plus réduites que celui du clos de Cybèle, cet édifice en reprend exactement les dispositions et cette similitude confirme les données de circulation proposées pour le réservoir étudié ici.

Un autre édifice vient confirmer cette hypothèse. En effet, à $120 \mathrm{~m}$ au n.-o. de la grande citerne, fin 1911, Fabia et Germain de Montauzan dégagèrent dans le clos du VerbeIncarné une construction mesurant $10,10 \mathrm{~m}$ sur $7,25 \mathrm{~m}$.

Il s'agissait d'une citerne à salles jumelles mesurant chacune $2,55 \mathrm{~m}$ sur $8,90 \mathrm{~m}$, séparées par un mur de $0,95 \mathrm{~m}$ dans lequel s'ouvraient trois passages de $0,75 \mathrm{~m}$ de large. Ce double réservoir, pavé en opus spicatum, dont les murs étaient, enduits de mortier à tuileaux avec moraines angulaires, était contrebuté par un remblai que contenait un mur extérieur enveloppant, donnant, à l'ensemble une longueur de $29,40 \mathrm{~m}$ sur une largeur non précisée, mais qui excédait $21 \mathrm{~m}$. Toutefois, la hauteur des murs n'excédant pas $1,50 \mathrm{~m}$, rien ne subsistait d'un étage supérieur. On retrouve ici l'utilisation d'une masse de maçonnerie et de terres pour contrebuter la poussée des eaux.

Le système n'est pas parliculier à Lugdunum. Le modèle en est la citerne de Firmium. Flle se compose d'une série de chambres voûtées de $9 \mathrm{~m}$ sur $6 \mathrm{~m}$, hautes de $5,20 \mathrm{~m}$ el disposées en deux étages. La circulation se faisait par des trous carrés réservés dans les voûtes, et par des baies cintrées, larges de $2,54 \mathrm{~m}$, hautes de $1,50 \mathrm{~m}$, unissant latéralement les chambres. On évoquera également le bassin de décantation de l'aqua Virgo à Rome.

L'existence des deux réservoirs secondaires de Fourvière résout un problème. La grande citerne du clos de Cybèle ayant été démolie avant 160, la distribution des eaux se fit ensuite grâce à la construction de petites citernes dont deux sont connues, à l'heure actuelle.

La visite des vestiges de la citerne de Cybèle révèle l'existence dans l'angle n.-o., de 
la nef occidentale, d'un bassin quasi carré mesurant intérieurement $2,15 \mathrm{~m}$ sur $2,24 \mathrm{~m}$, clos par un muret haut de $1,05 \mathrm{~m}$, épais de $0,35 \mathrm{~m}$ à $0,40 \mathrm{~m}$ marquant à son sommet un chanfrein extérieur haut de $0,23 \mathrm{~m}$. L'angle des deux parois est à pan coupé. Sur la face s., une encoche forme une vidange, ou surverse, à $0,82 \mathrm{~m}$ au-dessus du sol. Au pied de cette face, en dessous de l'encoche, un tuyau de plomb, encore en place, traverse la paroi et devait se terminer par un robinet, aujourd'hui disparu. En avant, le radier de la citerne est profondément éventré par un trou rond de 0,60 de diametre, dans lequel on pouvait placer un seau et le remplir grâce au robinct. Cé bassin fut aménagé postérieurement à l'abandon de la citerne; ses murs s'appuient contre les enduits et respectent les moraines. Il n'existait plus lorsque fut achevé le sanctuaire sous le campus duquel il fut profondément enterré. Dans l'entre-temps se situe l'utilisation du bassin, e'est-à-dire au cours de la construction du sanctuaire. Placé au-dessous du point d'arrivée de l'aqueduc, il pouvait être alimenté par une dérivation et servir aux maçons chargés de construire le sanctuaire. L'écoulement des eaux étail assuré par la pente du radier de la citerne en direction de l'égout de vidange, et c'est peut-être en vue de cet écoulement qu'un drain fut réservé au travers du mur du sanctuaire, comme cela a été signalé plus haut.

\section{IN. L'INST:IA "BAsILICALE"}

\section{DONNEES TOPOGRAPIIQUES}

Arasés lors de la construction du sanctuaire dont ils occupaient la partie orientale, gisent, scellés dans ses substructions, les vestiges d'une insula. Seule manque la partie occidentale, définitivement détruite par le creusement du réservoir de l'aqueduc. L'importance de cette insula dans le Lugdunum augustéen justifie une reprise des données topographiques la concernant.

Proche à la fois du decumanus (rue Cléberg) et de la rue d'Aquitaine (rue RogerRadisson), cette insula bordait une place qui constituait l'un des carrefours majeurs de la ville haute. Approximativement triangulaire, en forte pente n.-s., cette place mesurait quelque $50 \mathrm{~m}$ sur sa face o. et $25 \mathrm{~m}$ dans sa plus grande largeur, celle de la face $\mathrm{n}$. Sa forme irrégulière lui venait de ce qu'elle était bordée à l'e., sur $55 \mathrm{~m}$ environ, par la façade courbe de la cavea du théâtre d'Auguste.

Six rues desservaient cette place. A la pointe s., en son point le plus bas, débouchait la rue née à la porte Saint-Just et qui avait traversé les quartiers des thermes et de l'odéon. Au même point aboutissait, descendu de l'o. et du plateau, l'escalier, large de $3 \mathrm{~m}$, qui avait longé la face s. de l'insula.

Plus au n. s'ouvrait la rue, large de $3,40 \mathrm{~m}$, qui en avait longé la face $\mathrm{n}$. Entre les deux, l'insula marquait un désaxement de 14 degrés vers l'o. par rapport à l'axe de la rue montant de l'odéon, désaxement imposé par la présence débordante sur la droite de la masse du théâtre.

A l'opposé, de la pointe n.-e. de la place, partaient trois autres rues. La principale, dallée et large de $3,55 \mathrm{~m}$, rejoignait à la perpendiculaire la rue d'Aquitaine et servait de débouché principal à la circulation de la place. Du même point partait une seconde rue dallée, s'infléchissant vers l'e. pour longer la courbe du théâtre et en desservir les entrées supérieures, mais sans pouvoir, du fait de la dénivellation, rejoindre les parties basses de la façade. Enfin, toujours du même point, partait à gauche une ruelle, large seulement de $2,50 \mathrm{~m}$, parallèle à la rue d'Aquitaine, et qui, en montant, 
vers l'o., s'en allait rejoindre sous un angle aigu la rue longeant la façade n. de l'insula. Catte ruelle était portée par un mur de soutènement ascendant, long de quelque $18 \mathrm{~m}$, servant de fond à la place triangulaire. Très tôt, semble-t-il, de petites boutiques s'y adossèrent, réduisant d'autant la superficie de la place.

\section{L'INSULA (fig. 10 et 11 )}

Son orientation étant inclinéc de 3 degrés plus au n. que celle des édifices postérieurs, on n'éprouve aucune difficulté à en isoler les vestiges.

Délimitée sur trois côtés par l'escalier de $3 \mathrm{~m}$ au s., la place triangulaire à l'c., la rue de $3,40 \mathrm{~m}$ au n.. l'insula mesurait en largeur 125 picds, soit 37,20 m. De l'o. à l'e., elle devait atteindre 210 pieds, soit $62,40 \mathrm{~m}$. Cette estimation est étayée par la présence d'une rue transversale. Deux éléments connus, isolés l'un de l'autre par le sanctuaire de Cybèle, postulent l'existence initiale de cette rue qui aurait limité l'insula.

Cés données révèlent donc une composition conçue d'un seul jet sur un terrain rendu malcommode par la forte déclivité de la moitié orientale. Cette déclivité s'exprime par les cotes du sol aux quatre angles : au s.-c. 274,80, au n.-e. 280,50, au n.-o. 290,50, au s.-0. 292.

En fonction de cette irrégularité du sol, l'insula fit l'objet d'un lotissement complexe. En longueur, elle fut divisće en six tranches sensiblement égales. Ia plus orientale, large de $10,60 \mathrm{~m}$, fut réservéc à une file de boutiques ouvrant sur la place triangulaire. Les trois portions occidentales, soit la moitié du terrain, situées sur le plateau et larges de $31,07 \mathrm{~m}$ (105 pieds), le furent à des locaux administratifs. Le reste, soit deux sixièmes, eut une destination qui impose de l'étudier en premier pour ce qu'elle détermine la vocation des autres.

\section{IAA BASILIQUE (fig. 11 et 12 )}

Jans un rectangle de $37,20 \mathrm{~m}$ sur $20,35 \mathrm{~m}$, l'édifice s'étage sur trois niveaux en raison du profil du sol.

Le plan en est simple : deux rectangles emboités l'un dans l'autre. Un mur de 0,65 m en moyenne dessine le rectangle extérieur. Il est longé intérieurement par une galerie large de 4,50 m que limite d'autre part un mur épais de 1,25 m. Ce mur cerne un enclos central de 24,20 m sur 7,80 m.

On s'étonne de l'épaisseur relativement mince du mur externe par rapport à celle relativement forte du mur intérieur. Cela s'explique aisément. Én effet, le premier servail de soutènement sur les côtés n., o. et s. Taillé dans le lœss naturellement compact et stable, ce soutènement suffisait. Il en allait autrement du mur oriental érigé sur une grande hauleur malgré sa minceur apparente. C'est que la galerie orientale qui court entre les murs des deux rectangles plonge jusqu'au niveau de la place de telle manière que les boutiques pouvaient s'y adosser. Elle avait donc bénéficié d'un renfort particulier. Le mur intérieur de 1,25 m, qui, ici, traversait l'insula sur toute sa largeur, était doublé par un contre-mur de même épaisseur, tandis que le mur externe, porté à $0,78 \mathrm{~m}$ d'épaisseur, l'était également par un contre-mur de $0,68 \mathrm{~m}$. Ces deux murs de doublage, qui constituaient le niveau inférieur non praticable du système, portaient une vontte dont l'extrados se nivelait avec le sol de l'étage inférieur de l'édifice.

A ce second niveau, les deux rectangles constituaient un ensemble en sous-sol. De cet élage subsistent des restes importants, le mur interne occidental se haussant à la cote 289,68. Ces locaux, salle centrale et galeries externes, étaient praticables comme en témoigne la présence d'une fresque à personnages dans la galerie o. Aucune communication directe n'étant possible avec l'étage supérieur, 


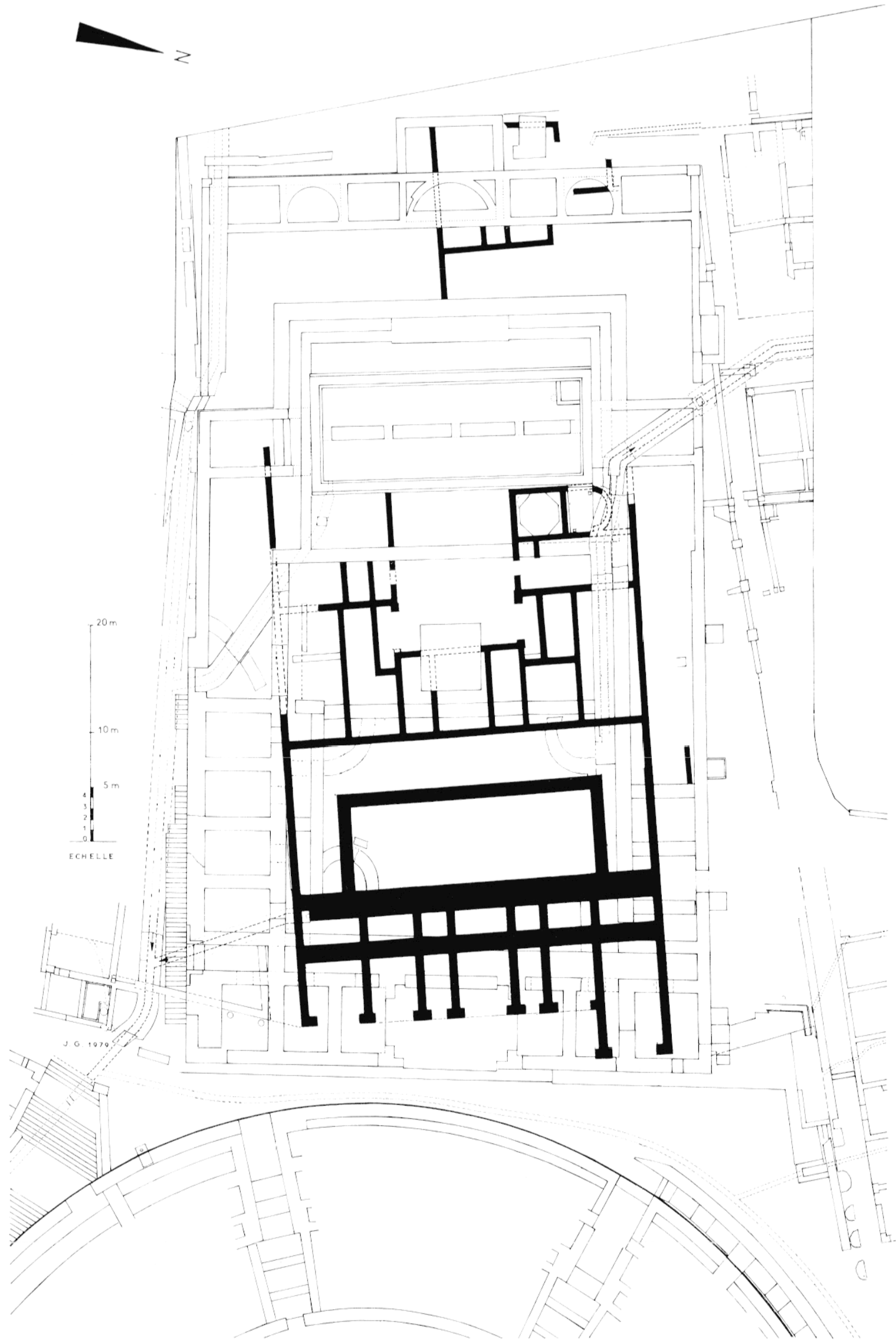

10 Substructions de l'Insula, boutiques comprises. 


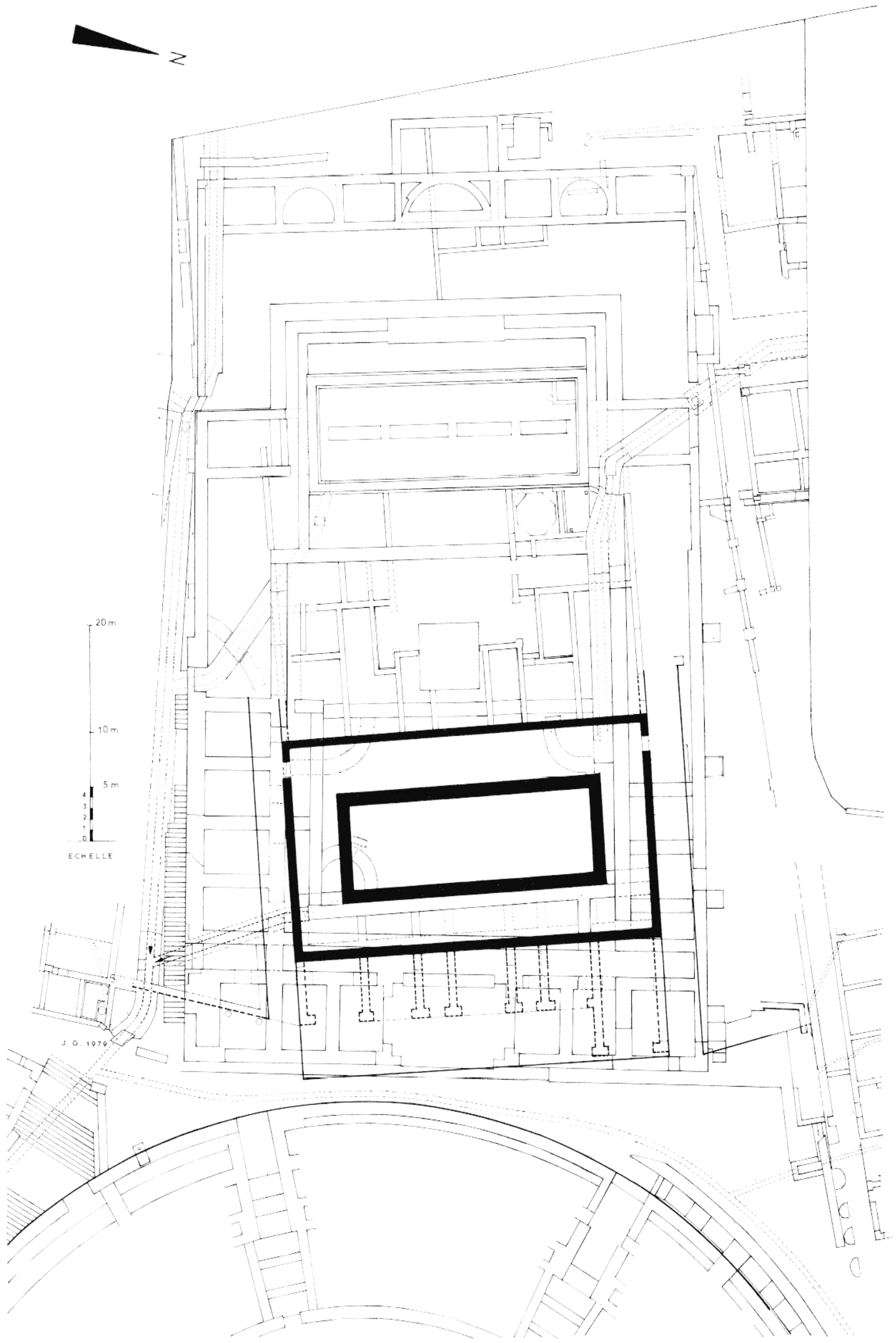

11 La basilique inférieure et son égout. 


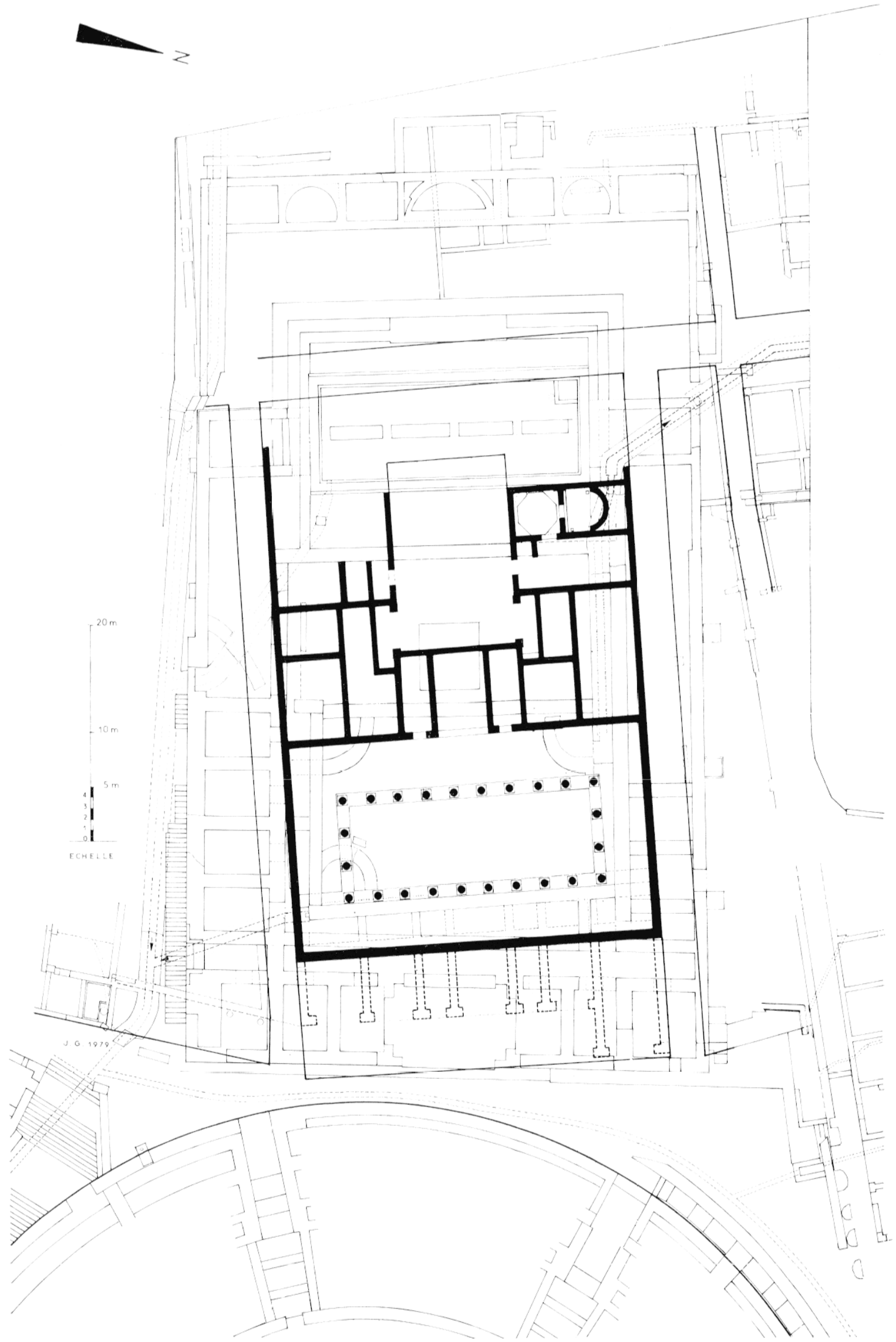

12 Essai de restitution de la basilique supérieure ef des locaux administratifs. 
on admettra qu'ils étaient accessibles par des portes ouvranl dans les façades n. et s., sans doute au droit de la galerie occidentale, le plus loin possible des zones basses de la place triangulaire. Ces portes étaient en liaison avec les deux voies, rue et escalier, longeant l'insula.

L'existence d'un étage supérieur, nivelé avec les locaux occupant la moitié o. de l'insula, au niveau du plateau, pose un problème. Comment élaient couvertes les salles de l'étage inférieur ? Le fait que le mur o. ne livre pas trace de voûtes implique que les locaux inférieurs étaient couverts en charpentes pouvant porter des dalles. Cette solution réglerait la question de l'éclairage de ces locaux, au moins en ce qui concerne la galerie o. ornée de fresques. Elle permet de supposer l'existence de grilles de sol. Les galeries n., e. et s. pourraient aussi prendre jour directement sur l'extérieur, mais rien ne permet de suggérer cette hypothèse.

Toute tentative de restitution se fonde sur l'épaisseur anormale du mur du rectangle intéricur. Large de $1,25 \mathrm{~m}$, il avait, de toute évidence, une fonction précise, celle de stylobate. Or de nombreux éléments de colonnes sont apparus aux abords immédiats. Ils révèlent que les dés de base mesuraient plus de $1 \mathrm{~m}$ de côté, ce qui s'accorde avec l'épaisseur du mur stylobate. Ainsi supposc-t-on un portique comportant, sur les côtés longs, 10 colonnes avec entraxes de 2,80 m, sur les côtés courts, 4 colonnes avec entraxes de $3,10 \mathrm{~m}$. Ce portique séparait la salle centrale des galeries qui l'enveloppaient sur les quatre faces. On retrouverait là le plan basilical classique, la salle centrale étant éclairée par des baies à clauslrae ouvertes dans un attique coiffant le portique et soutenant une toiture en charpente à deux ou quatre pans. Les galeries périphériques étaient couvertes par une toiture à simple pente établic au-dessous des baies de l'attique. Disposition traditionnelle, celle de la basilique Julia, au forum romain.

Une basilique devait posséder une tribune. Impossible ici de la loger sur les deux côlés courts qui longeaient des voies publiques. Le côté e., perché au-dessus des boutiques et de la place, ne scmblc pas à retenir. En trouvera-t-on les traces dans les locaux administratifs étalés à l'o.? De plus, l'existence d'un local public d'une superficie de plus de $650 \mathrm{~m}^{2}$ impliquait l'obligation d'un lessivage à grande eau, donc d'un dégagement avec mise à l'égout. On devra tenir également compte du passage à travers les baies de la salle centrale des eaux de pluies et de leur débouché dans le grand collecteur qui longe la face s. du sanctuaire, dont il est assuré qu'il est antérieur à celui-ci, malgré les remaniements que lui imposera sa construction. De la face s. du sanctuaire de Cybèle, à $10 \mathrm{~m}$ de l'angle s.-e., émerge un égout qui ne peut plus déboucher dans le collecteur, son radier étant inférieur de $0,50 \mathrm{~m}$. On peut done affirmer que, dans un état premier, le collecteur avait un radier plus bas lui permettant de recueillir les caux du petit égout venu du n. Ce remanicment est consécutif au relèvement de la portion s. de la place triangulaire. Or cet égout, comme le collecteur, possédait un radier de briques. Lors de l'exploitation médiévale des ruines antiques, on vint arracher non seulement les briques du collecteur, mais aussi celles du secteur terminal du petit égout, déchaussant pour cela la base des murs piédroits. Le mur du sanctuaire, construit postérieurement au petit égout, l'avait comblé en détruisant les murs jusqu'au radier. Cela ne rebuta pas les prédateurs qui le recreusèrent pour poursuivre leur exploitation le plus loin possible. De cettc observation ressort que l'antériorité du petit égout est bien assurée. On est donc fondé à prolonger son cours initial jusqu'au contact de l'édifice basilical, à $16 \mathrm{~m}$ de son débouché dans le collecteur. 
Les dimensions de ce petit égout sont modestes. Large de $0,62 \mathrm{~m}$, il a des parois de granit de $0,50 \mathrm{~m}$ d'épaisseur, hautes de $0,98 \mathrm{~m}$ et mesurait $1,29 \mathrm{~m}$ sous clef. Les murs furent entaillés à la base sur $0,12 \mathrm{~m}$ pour l'extraction des briques du radier. Celui-ci, sur une couche de béton, était conslilué de trois rangées de briques de $0,32 \mathrm{~m}$ sur $0,46 \mathrm{~m}$ et $0,045 \mathrm{~m}$, posées en arêtes de poisson sur une largeur de $0,86 \mathrm{~m}$. Les extrémités de ce lit étaient donc prises sous les murs piédroits. Aucune brique n'apparaît, dans ces murs, pas plus que dans la voûte qui affecte extérieurement un profil arrondi.

Or, le mur séparant la nef centrale de la basilique du couloir oriental traverse loute l'insula et plonge à un niveau très inférieur à celui de la basilique souterraine. Dans l'angle intérieur de ce mur et de celui qui limite l'insula par le s. existe un tabouret de $0,46 \mathrm{~m}$ sur $0,50 \mathrm{~m}$, fait de briques de $0,42 \mathrm{~m}$, dont la face supérieure est cotée 281,50 . A partir de la basilique supérieure, les eaux usagées devaient atteindre ce tabouret par une conduite verticale en céramique dont il n'est rien demeuré, rejoindre le départ de l'égout, passer sous l'escalier bordant par le s. l'édifice basilical et déboucher finalement dans le collecteur primitif.

LES LOCAUX ADMINISTRATIFS (fig. 1:3)

Sur le plateau, entre basilique et citerne, s'étend une large surface coupée par un réseau de murs, oscillant entre $0,55 \mathrm{~m}$ ct $0,63 \mathrm{~m}$ d'épaisseur, arasés systématiquement au niveau du sol lors de la construction du sanctuaire. Entre ces murs s'étalent des plaques de sol en opus signinum blanc, épais de $0,023 \mathrm{~m}$ à $0,03 \mathrm{~m}$, posées sur un cailloutis de "têtes de chat" de $0,10 \mathrm{~m}$ à $0,20 \mathrm{~m}$, le tout coté 291,70 lorsque les sols sont demeurés de niveau au contact des murs, mais s'abaissant notablement en s'en éloignant par suite du tassement du remblai sous-jacent. Partout où cela est possible, on observe la présence d'un premier sol nivelé à $0,07 \mathrm{~m}$ plus bas, témoin d'un "rechapage " réparateur. Murs et sols, partiellement détruits par le creusement de la citerne, arasés par la construction du sanctuaire, ont, à une date récente, été profondément altérés par la plantation d'un verger, alors qu'ils étaient couverts par un remblai si mince qu'il n'a guère pu les protéger.

Aussi est-il malaisé de retrouver l'ordonnance de ces locaux, en particulier vers l'o. Toutefois, s'ils disparaissent à $22 \mathrm{~m}$ de la basilique dans les excavations de la citerne, le mur s., qui échappa à celles-ci, a été suivi jusqu'à $27,20 \mathrm{~m}$. On l'a vu, sans doute l'ensemble s'étendait-il jusqu'à la rue transversale, à $31,07 \mathrm{~m}$ de la basilique.

Au centre de ce complexe s'affirme l'existence d'une salle large de $11,90 \mathrm{~m}$, dont la longueur dépassait $14 \mathrm{~m}$ avant les dégradations dues à la construction de la citerne. Le sol est de niveau avec celui des locaux circonvoisins et, dans une embrasure, se voit même leur ligne de raccord. Bien que ce nivellement ne joue pas en faveur de telle interprétation, par simplification terminologique, on qualifiera cependant de cour cette vaste salle centrale.

Entre cour et basilique se distingue un corps de bâtiment, ne serait-ce que par son sol de mortier à tuileaux dont il subsiste un lambeau. Prolongeant exactement la cour et appuyé contre la basilique, il était long de 24 pieds, soit 7,02 m, et divisé en trois travées symétriques sur l'axe transversal de la basilique. Il pourrait s'agir d'un tribunal, voire d'une curie ${ }^{22}$. La travée centrale était large de 17 pieds, soit 5,03 m, les deux autres de

2:2 Voir l'étude de J.-Ch. BatrY ; C'uria Ordinis. Recherches d'archileclure et d'urbanisme antiques sur les curies provinciales du monde romain, Université de Bruxelles; these dactylographiée, 1967, et K. Oır, Die Form der Basilika vei Vitruw, dans Bonner Jahrbücher, 175, 1975, p. $113 \mathrm{sq}$. 


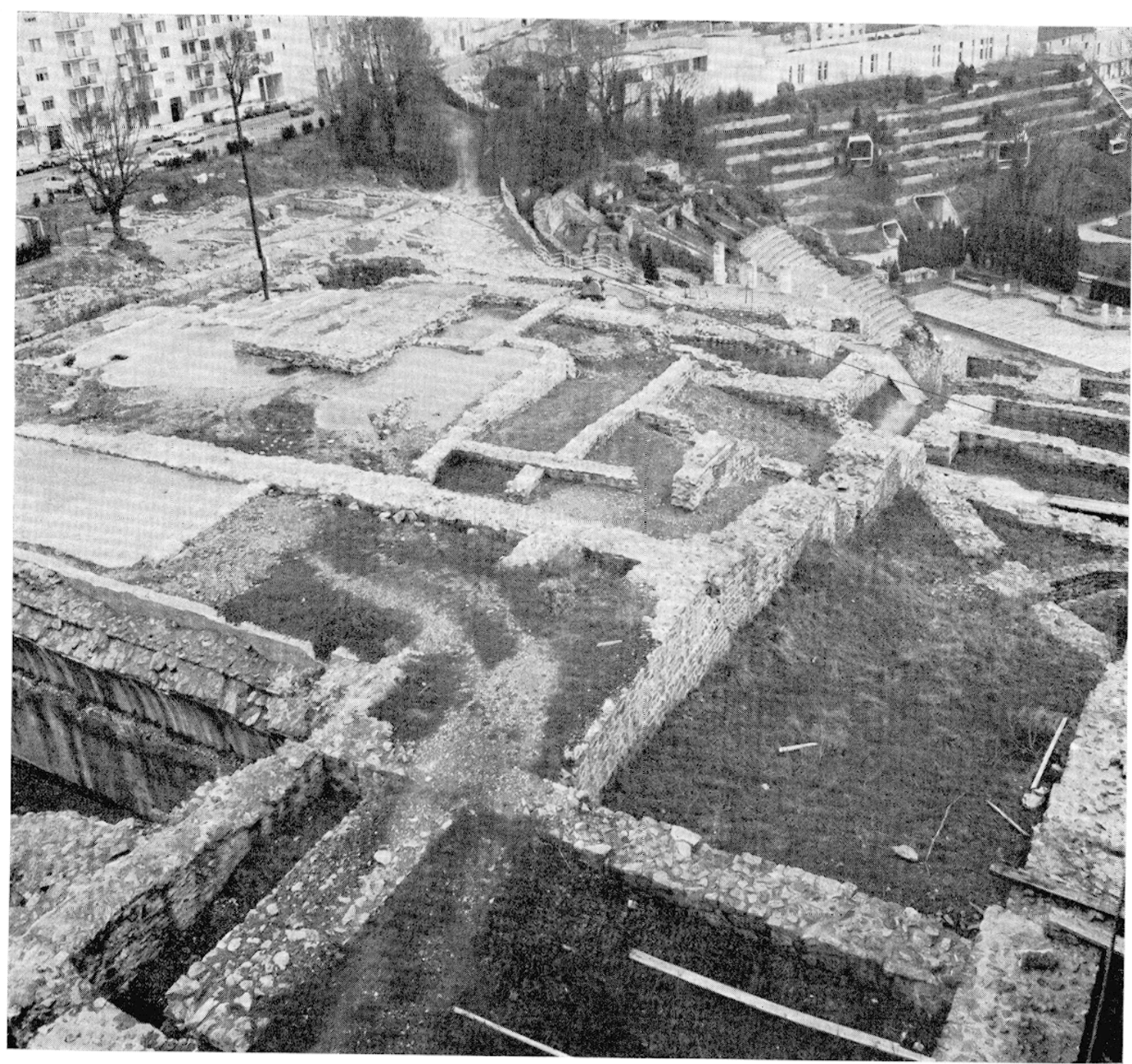

13 Les locaux administratifs vus de la maison des Cèdres.

10 pieds $(2,92 \mathrm{~m})$. Constituaient-elles des couloirs d'accès à la tribune avec escaliers, ou des secrétariats?

Tronquée en son extrémité o., la cour n'a pas révélé sa longueur. On peut estimer qu'elle était séparéc de la rue par une clôture, peut-être avec portique. Ainsi toute la partie centrale des locaux : portique éventuel, cour et tribune, divisait l'insula en deux parties égales, larges de $12,50 \mathrm{~m}$, mais entre lesquelles la symétrie n'était pas absolue. Il est d'autant plus malaisé de retrouver l'économie de ces ailes que les franges n. et s. en ont été profondément bouleversées sur une largeur de plus de $6 \mathrm{~m}$ par l'établissement des deux égouts de la cour du sanctuaire, égouts dont la destruction a encore hâté celle des locaux administratifs. Au surplus, l'établissement du mur de renfort oriental de la citerne recoupa ceux des locaux sur une largeur de 5 à $6 \mathrm{~m}$ à l'e. de ce réservoir.

Dans ce réseau mutilé paraissent cependant deux constantes. L.es ailes étaient recoupées 
transversalement par un mur courant à 40 pieds, $11,84 \mathrm{~m}$, à l'o. de la basilique. La portion intermédiaire était redivisée longitudinalement par un mur implanté à 17 pieds $(4,85 \mathrm{~m})$ de la cour et à 20 pieds $(5,97 \mathrm{~m})$, du mur extérieur. Au n. et au s., la cour était longée par un couloir large de 1,60 m. Celui du n., moins altéré, était accessible de la cour par deux baies, l'une, à l'o., large de 1,32 m, l'autre, à l'e., de 2,95 m. De la cour on gagnait donc la basilique en utilisant successivement la baie de l'e., le couloir et la pièce de $4,85 \mathrm{~m}$ sur $5,50 \mathrm{~m}$ qui flanquait le corps de la tribune. D'une pièce contiguë à la précédente, qui mesurait $5,92 \mathrm{~m}$ sur $11,84 \mathrm{~m}$, il est impossible de préciser la destination.

Sans quitter l'aile $\mathrm{n}$., revenons à la petite baie ouverte au-delà du mur transversal. Elle donne accès à un modeste établissement thermal constitué d'abord par une salle de $9 \mathrm{~m}$ sur 4,40 m, occupant toute la largeur de l'aile. Totalement détruite par la construction du mur de renfort de la citerne, cette aile, qui pouvait être un frigidarium, a livré dans le remblai une quantité de fragments de sol mosaïqué noir et blanc, orné de panneaux et de feuilles cordiformes. A l'o. était un caldarium sur hypocauste, de $2 \mathrm{~m}$ sur $5 \mathrm{~m}$. A gauche, une salle octogonale de $5 \mathrm{~m}$ sur $5 \mathrm{~m}$, peut-être un tepidarium, a conservé dans une niche occupant le côté s.-o., un élément de mosaïque sur mortier à tuileaux. A droite, une grande abside fut détruite par la construction de l'égout du sanctuaire, en même temps que la chaufferie des thermes.

L'existence de ceux-ci exigeait un dégagement des eaux usées. Un égout est effectivement apparu là où on l'attendait. Détruit en ses trois premiers mètres par les travaux du sanctuaire, il paraît ensuite selon un tracé oblique, sortant du sanctuaire sous la porte $n$. de celui-ci, où existait un regard. A $18,50 \mathrm{~m}$ de son origine, un coude au $\mathrm{n}$. lui donne l'axe de la rue transversale par laquelle il rejoignit le collecteur de la rue d'Aquitaine. Il a été suivi dans cette direction sur $25,30 \mathrm{~m}$. Au total, son exploration a porté sur $43,80 \mathrm{~m}$. Un peu avant le coude, en sa portion oblique, il recevait du s. une arrivée que marque encore le vide d'un tuyau. A $15 \mathrm{~m}$ après le coude débouchait du s. un diverticule oblique provenant de l'immeuble riverain.

Contemporain de l'égout du s.-e. de la basilique auquel il ressemble trait pour trait, il s'inscrit dans un massif large de $1,45 \mathrm{~m}$ arrondi au sommet, posé sur un radier de briques de $0,32 \mathrm{~m}$ sur $0,45 \mathrm{~m}$ et $0,045 \mathrm{~m}$, dressées de chant en arêtes de poisson. Large intérieurement de $0,60 \mathrm{~m}$, il offre des piédroits hauts de $1 \mathrm{~m}$ et une voûte de $0,30 \mathrm{~m}$ de flèche, dont la clef est épaisse de $0,38 \mathrm{~m}$. La hauteur sous voûte, actuellement de 1,62 m, l'était de 1,30 avant déchaussement du radier. La maçonnerie de granit sans inclusion de briques ne comporte aucun enduit. Le regard, situé sous l'angle de deux murs du sanctuaire à la porte $\mathrm{n}$, est de briques comme le montre la face s. demeurée en place. Ici, la voûte était faite d'une vingtaine de briques en claveaux, longues de $0,30 \mathrm{~m}$, épaisses de $0,04 \mathrm{~m}$ à $0,06 \mathrm{~m}$.

Dans la partie s. de l'égout, quasi totalement spoliée, on distingue encore dans le mortier l'empreinte du double chevron inversé laissé par les briques.

Profondément dégradée, l'aile s. ne permet guère de distinguer que la large porte, symétrique à celle de l'aile $n$., donnant accès au couloir atteignant la basilique. La petite porte voisine a disparu sous les terrassements de la citerne. Du reste, les vestiges sont peu cohérents, la partie située au-delà du mur transversal ayant été détruite, tant lors de 
l'établissement de l'égout de décharge de la citerne que de l'érection du mur soutenant la masse de terre contrebutant celle-ci.

\section{LES BOUTIQUES}

Une question se pose d'abord à leur propos. Pourquoi, dans un ensemble municipal, avoir abandonné une zone à des entreprises privées? Ia réponse sc lit dans le relief : depuis la place triangulaire, la dénivellation du sol interdisait tout accès direct aux portes de la basilique inférieure; en revanche, l'espace mort qui longeait latéralement ces boutiques permettait d'établir des voies atteignant ces portes. Si l'on admet que celles-ci ouvraient aux extrémités de la galerie 0 , un espace de $28 \mathrm{~m}$ au n. amortissait une dénivellation de quelque $8 \mathrm{~m}$. Au s., où parurent les restes d'un escalier, $20 \mathrm{~m}$ permettaient d'atteindre une porte à un niveau surélevé de $11 \mathrm{~m}$.

Entre des murs latéraux de $0,75 \mathrm{~m}$, sauf le plus septentrional, épais de $0,90 \mathrm{~m}$ en fonction de son rôle de soutènement de la rue latérale, sept bouliques de largeurs inégales s'ordonnaient symétriquement de part et d'autre de l'axe de l'insula.

Celle du n., profonde de 10,22, alignait sa façade à $4,10 \mathrm{~m}$ en avant des autres. Cette avancée répond au besoin, signalé plus haut, de réserver le plus grand développement possible à la rue qui la longeait au n. pour atteindre sous une moindre pente la porte de la basilique inférieure.

Quant aux autres boutiques, le retrait devait en être occupé par un portique en paliers successifs. Au droit des têtes des murs de refend en forme de $\mathrm{T}$, larges de $1,70 \mathrm{~m}$, des volées de quatre ou cinq marches unissaient les paliers. Un mur bahut séparait le portique de la rue et portail des piliers soutenant la toiture. On devait accéder au portique par une ouverlure du mur bahut devant la seconde boutique à partir du n. pour en sortir par un escalier existant au débouché s. du portique. Mur bahut et piliers ont disparu lors de la construction du mur de façade e. du sanctuaire de Cybèle, mais on constate qu'ils s'alignaient, d'une part avec la façade de la boutique n., de l'autre avec celle des boutiques de la rue descendant vers les thermes.

Non sans étonnement, et dans l'impossibilité d'expliquer le fait, on observe une étroite correspondance entre le rythme irrégulier des boutiques et celui des locaux administratifs situés de l'autre côté de la basilique.

$$
\begin{array}{lll}
\text { Locaux administratifs.... } & 5,92 ; 4,84 ; 2,93 ; 5,03 ; 2,93 ; 4,85 ; 5,92 \mathrm{~m} \\
\text { Boutiques............ } 5,82 ; 4,66 ; 2,60 ; 5,21 ; 2,60 ; 4,65 ; 5,65 \mathrm{~m}
\end{array}
$$

Telle symétrie n'est pas le fait du hasard. Si on ne peut l'expliquer, du moins est-elle la preuve que l'insula fut conçue en un seul temps et sur un plan qui en incluait tous les éléments.

Protégées par les remblaiements consécutifs à la construction du sanctuaire, les boutiques ont conservé quelques traces de décor, en particulier la plus méridionale (fig. 14).

Son mur s. traverse le second alvéole et son mur n. le troisième. Ils rejoignenl, dans le couloir de desserte, le mur de fond de la boutique, laquelle mesurait $5,82 \mathrm{~m}$ de large sur $5,37 \mathrm{~m}$ de profondeur, sans compter les retours en 'T de l'embrasure de $5,08 \mathrm{~m}$. La tête du mur méridional n'a láissé qu'un soubassement : marquant l'angle de l'insula, elle était en pierres de laille qui furent exploitées. La tête du mur n. partiellement conservée, est en lits réguliers de granits taillés, avec arases de rangées de briques. 


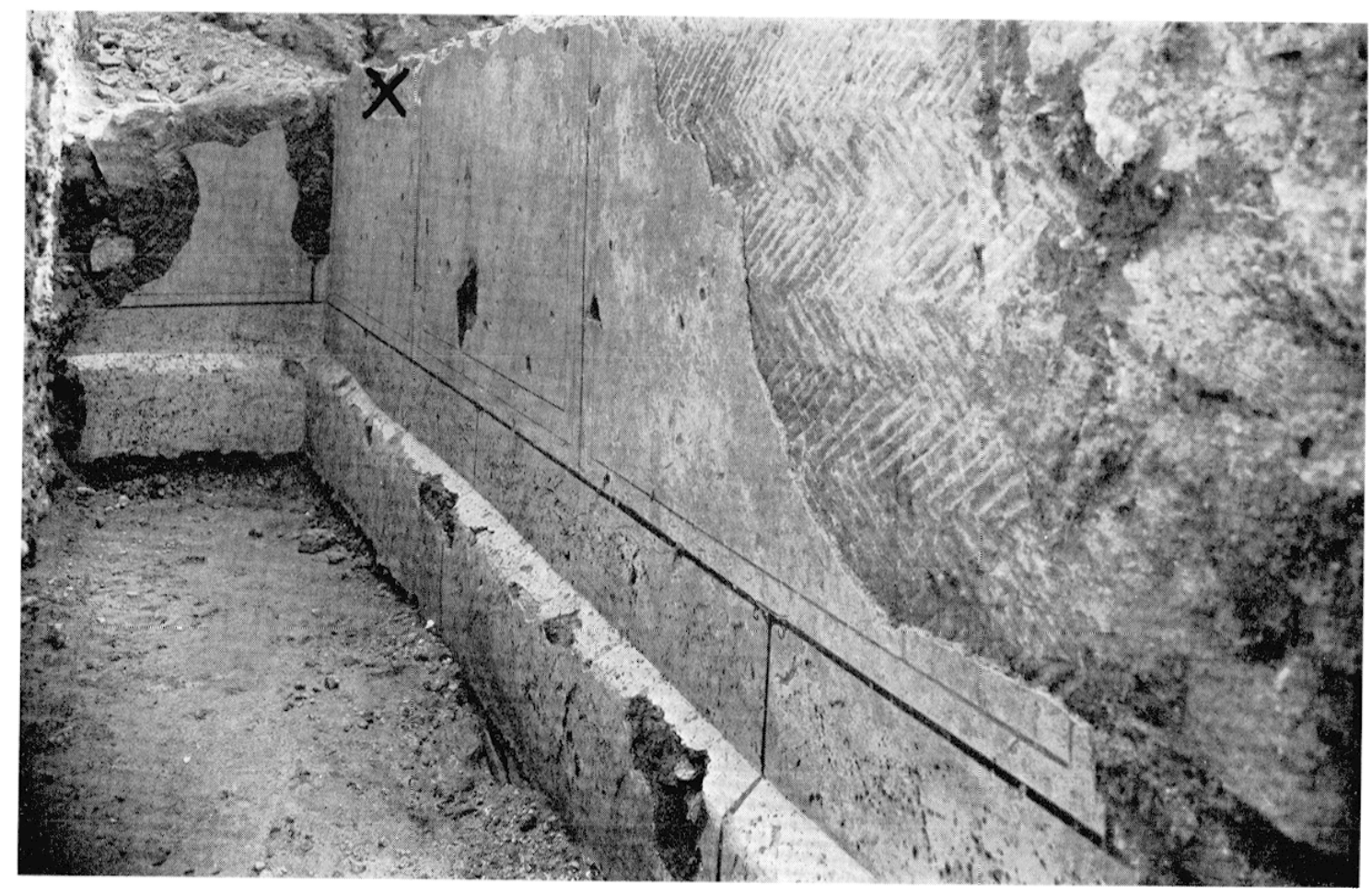

$1 . t$ I.e fond de la boulique meridionale visible dans le couloir des alvéoles du sanchuaire.

lat croix, en haut, indique l'emplacement d'une fresque représentanl un oiseau beu.

15 Fragment de fresque tigurant un aurige, ... trouvé en 1943 dans la boutique méridionale.

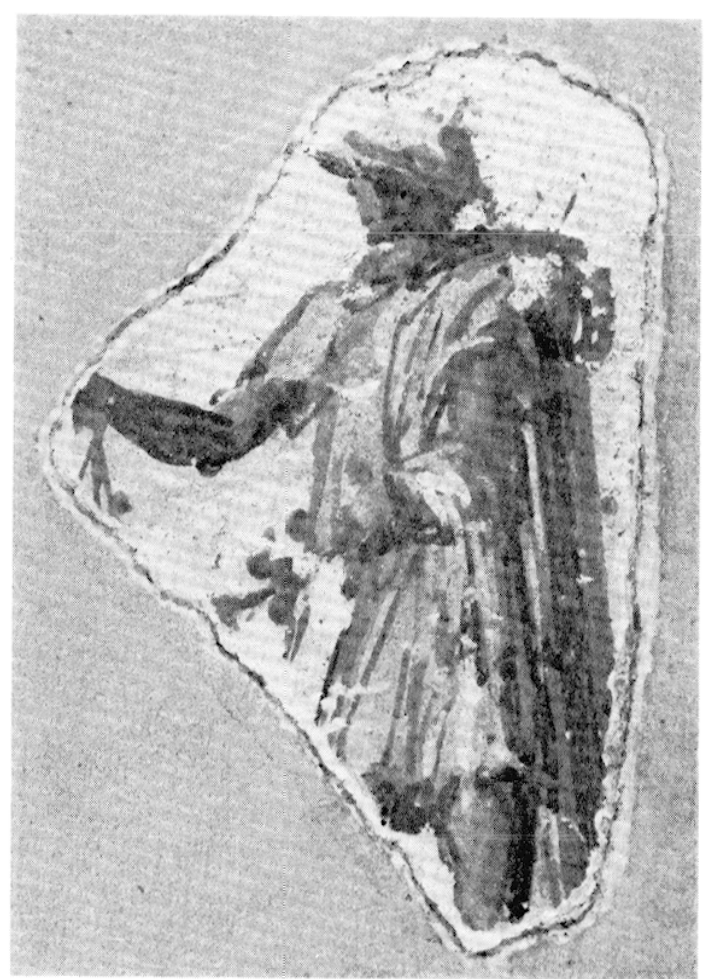

Sauvegarde sur une hanieur de 1, f) m, le mur de fond ivre un enduil hane, posi sur un dégrossissage de morlier en arèles de poisson pour assurer la prise de l'enduil. Au bas, une plinthe de 0,30 $\mathrm{m}$ est amorlie par un chanfrein de 0,05 $\mathrm{m}$. A $0,19 \mathrm{~m}$ plus haut, un tilet noir limite ce soubassement entièrement lacheté au pinceau de mouchetures noires el rouges el coupé verticalement par 
quatre filets noirs, coiffés au contact du filet horizontal par des fleurons à volutes en manière de chapiteau ionique.

La zone supérieure comportait quatre panneaux axés sur les filets à chapiteaux du soubassement et séparés par des filets noirs, les deux extrêmes tracés a $0,06 \mathrm{~m}$ des angles de la boutique. Ils mesuraient respectivement, du s. au n., 1,37 m, 1,39 m, 1,41 m et 1,47 m. Les deux derniers sont partiellement détruils. Chacun était cerné par un second filet, rouge, à $0,06 \mathrm{~m}$ du précédent. Le second comportait un troisième filet, noir à $0,06 \mathrm{~m}$ du rouge. Le centre de ces panneaux s'ornait de motifs figurés; malheureusement l'arasement régulier du mur au niveau d'une poutre horizontale dont on reparlera n'en a laissé subsister qu'une faible partie, qui d'ailleurs s'effrita immédiatement. On en est réduit à la description des terrassiers. Dans le premier aurait été vu un pigeon bleu, de profil à droite, picorınt une plante. Le second révéla, à gauche, quatre jambes féminines entrelacées en une attitude de danse, à droite une jambe masculine brune, peut-être celle d'un flutiste. Un élément provenant sans doute du troisième montrait une queue de poisson d'un noir violet. Est-ce du quatrième que vient le fragment figurant un aurige tourné à gauche, casqué, portant tunique courte et manteau, d'un dessin prestement enlevé et qui fait honneur à son auteur (fig. 15). Ce décrr retournail sur les parois latérales.

L'embrasure de la façade étail partiellement obturée par une maçonnerie où se voyait l'empreinte creuse d'une amphore. Il s'agissait vraisemblablement d'un thermopolium du type de ceux d'Ostie et de Saint-Romain-en-Gal. Un sol bétonné, large de $0,90 \mathrm{~m}$, restait en place devant la baie.

De la seconde boutique, large de $4,66 \mathrm{~m}$, le couloir montre les arrachements des murs latéraux sur celui du fond. Le sol, nivelé à $0,45 \mathrm{~m}$ plus haut que celui de la première boutique, implique l'existence de trois marches devant la tète du mur mitoyen.

Le mur de fond de cette boutique est haut encore de $2 \mathrm{~m}$. L'enduit blanc en est détruit jusqu'à $0,56 \mathrm{~m}$ du sol, preuve de la présence d'une saillie correspondant au départ d'une plinthe systématiquement abattue. $\mathrm{Au}$-dessus de cette plinthe, l'enduit est nu sur $0,37 \mathrm{~m}$ et limité par un filet noir horizontal de 0,005 $\mathrm{m}$ au-dessus duquel s'ordonnait le décor. Par malheur, à $0,12 \mathrm{~m}$ plus haut le mur est creusé par la grande coupure horizontale de la poutre qui prolonge celle de la boutique voisine. Haute de $0,16 \mathrm{~m}$, profonde de $0,18 \mathrm{~m}$, elle est encore enduite de mortier et retourne dans le mur $\mathrm{n}$. de la seconde boutique. Le mur s. est trop démoli pour en rien révéler.

$\Lambda u$-dessus de la coupure s'étalait une plage s'étendant jusqu'à une seconde coupure nivelée à $0,88 \mathrm{~m}$ plus haut. Ainsi put-on retrouver les éléments du décor modeste qui ornait la partie s. sur une largeur de $2,95 \mathrm{~m}$. Il était constitué simplement de filets noirs dessinant trois panneaux dont la hauteur peut être estimée à $1,30 \mathrm{~m}$. Ils laissaient de chaque côté une bande vide de $0,09 \mathrm{~m}$ et au-dessous une autre de $0,06 \mathrm{~m}$ jusqu'au filet déjà signalé et qui, par la maladresse du fresquiste se relevait sensiblement sur la droite. Les deux panneaux extérieurs mesuraient $0,92 \mathrm{~m}$ de large. Celui du centre était réduit à $0,68 \mathrm{~m}$ par deux autres filets alignés à $0,14 \mathrm{~m}$ de ceux des panneaux extérieurs. Dans celui du centre, un filet noir dessinail un grand losange aux pointes tangentes au cadre, ce qui a permis d'en calculer la hauteur malgré la destruction du mur.

Au nord, l'enduit montre une interruption impliquant que le reste de la boutique avait, sur $1,90 \mathrm{~m}$, reçu un décor particulier dont les traces sont insignifiantes. On reconnait un filet vertical noir à $0,06 \mathrm{~m}$ de l'angle $\mathrm{n}$. et, entre les deux, un second, gris très clair. Les filets étaient épais de $0,006 \mathrm{~m}$. A noter que la maçonnerie avait, dans cette salle, reçu une première couche de dégrossissage de mortier gris épaisse de $0,007 \mathrm{~m}$. Une seconde, blanche, portait le décor.

Des deux murs, distants de $2,60 \mathrm{~m}$, qui déterminaient la troisième boutique, ne restent que peu de traces. Toutefois un enduit subsistait sur le mur de fond. Au-dessus d'une plinthe lisse à fond blanc paraît un filet horizontal noir. Immédiatement au-dela, trois panneaux dessinés par d'autres filets noirs de $0,006 \mathrm{~m}$. A gauche, le panneau est séparé de l'angle par une bande de $0,06 \mathrm{~m}$, à droite de $0,065 \mathrm{~m}$. Les trois panneaux mesurent $0,66 \mathrm{~m}, 1,15 \mathrm{~m}$ et $0,68 \mathrm{~m}$. Ceux de l'extérieur sont redoublés intérieurement, à $0,035 \mathrm{~m}$ du cadre, par un filet rouge de $0,005 \mathrm{~m}$. Du décor qui devait animer ces 
panneaux, et spécialement le grand du centre, rien n'est demeuré. En revanche, on distingue sur l'amorce des murs latéraux de la boutique le prolongement du même dessin.

Ia quatrième boutique n'a livré qu'un mince élément décoratif, mais plus riche que les autres. A $0,06 \mathrm{~m}$ de l'angle s., toujours sur fond blanc, parait un filet noir de $0,007 \mathrm{~m}$, puis à $0,035 \mathrm{~m}$, un filet rouge de $0,005 \mathrm{~m}$. Au-delà, après un vide de $0,155 \mathrm{~m}$, se dessine une couronne de $0,29 \mathrm{~m}$ de diamètre, constituée par un filet rouge, coupé au bas par un carré placé sur la pointe, fait d'un filet rouge avec point central rouge et points également rouges sur les angles supérieur et inférieur. Latéralement, le carré est isolé de la couronne par deux gros points verts. Le sommet de celle-ci ne présente pas de carré, mais seulement les deux points verts symétriques à ceux du bas. Enfin, chaque moitié de la couronne est coupée en trois par deux fleurons composés d'un petit cercle avec quatre pointes vertes, séparées par quatre points rouges.

Le mur de fond disparaît immédiatement sous les maçonneries du sanctuaire. Il n'est donc rien demeuré du décor des autres boutiques. On note cependant, dans le mur séparant les deux dernières au n., le vide d'une poutre horizontale de bois.

Le vif intérêt présenté par ces décors, pour fragmentaires qu'ils soient, est qu'ils paraissent n'avoir subi ni reprises ni surchages comme cela a été observé dans une boutique proche de l'odéon. Ici, un seul enduit couvre la maçonnerie et l'on est fondé à penser qu'il est contemporain de l'aménagement de l'insula basilicale.

\section{IOATATION IIE L'INSLILA}

Avant même que les fouilles n'atteignissent le sanctuaire de Cybèle, elles avaient livré des tambours de colonnes ayant roulé dans la cauea du théâtre en perdant toute la saillie de leurs cannelures. Le dégagement des alvéoles du sanctuaire en fit reparaitre d'autres, en meilleur état. Nous disposons aujourd'hui de 12 tambours à 22 cannelures, dont la hauteur oscille entre $0,47 \mathrm{~m}$ et $0,62 \mathrm{~m}$, mais dont le diamètre maximum, le plus proche de la base, atteint $0,74 \mathrm{~m}$. D'où l'on peut inférer que la colonne mesurait $6,75 \mathrm{ml}$ de hauteur, avec un entablement de $1,70 \mathrm{~m}$, au total $8,45 \mathrm{~m}$. L'emploi d'un calcaire tendre et gris date l'édifice d'une époque antérieure au règne de Claude et à la mise en exploitation intensive du calcaire blanc et dur du Bas-Bugey.

Telle datation est renforcée par l'analyse des maçonneries, rigoureusement semblables à celle du théâtre augustéen. Elles sont en lits brouillés et construites par banchées moyennes de $0,65 \mathrm{~m}$, les gros blocs en bas, les moyens par-dessus, l'arasement supérieur étant obtenu par du petit matériel mêlé de quelques fragments de briques. D'ailleurs, l'emploi de celles-ci répond à un dessein précis. Pas d'arases comme un siècle plus tard, mais utilisation systématique des briques dans les arêtes des embrasures où, par rangées simples, doubles ou triples, elles alternent avec des blocs de granit bien taillés de manière à livrer des angles nets et solides.

Revenant aux colonnes, dans lesquelles il faut voir celles de la basilique supérieure, on a trouvé un élément plus précis encore. Le dégagement du premier alvéole s. du sanctuaire livra deux blocs provenant l'un et l'autre de la moitié inférieure d'un chapiteau corinthien de même matériau et de dimensions correspondant aux colonnes. Leur style, le fait que les larges acanthes plates dessinent des "yeux" obtenus par contact de la pointe de deux 


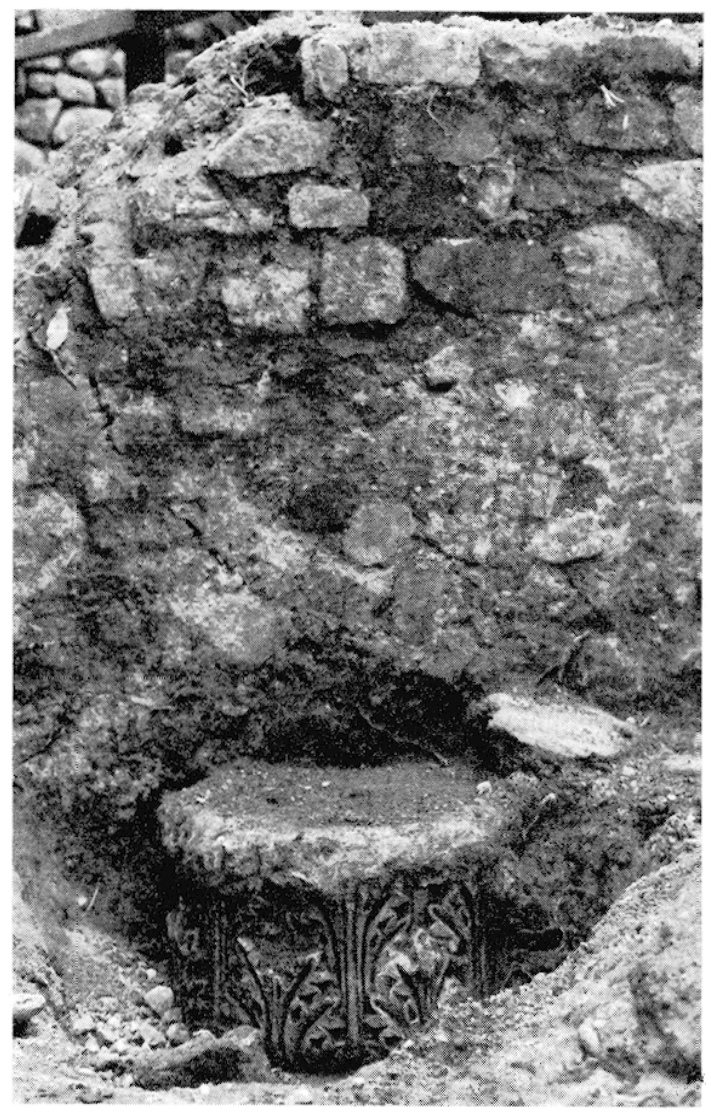
trouvée dans l'alvéole s.

folioles, celui aussi que les chapiteaux soient en deux pièces, justifient une datation augustéenne, pleinement confirmée par M. Ward Perkins (fig. 16) ${ }^{23}$.

La remise en état du bassin d'où sortait l'égout s. du sanctuaire a fait apparaitre un mur de mauvaise maçonneric appuyé contre la paroi de la galerie o. de la basilique inférieure. La restauration de ce mur a permis de dégager un élément de fresque pariétale. Sur fond blanc, dans un cadre cerné par un filet noir externe et un filet intérieur plus clair, cette fresque figure, sur un sol d'où émergent quelques maigres végétaux, deux pygmées, en tuniques courtes, celui de gauche armé d'un épieu, celui de droite d'une lance, attaquant une grue aussi grande qu'eux et tournée à gauche. Il s'agit là d'une scène nilotique, en grande faveur à l'époque d'Auguste, qui constitue, si l'on peut dire, le style "Retour d'Égypte » qui confirme la datation proposée (fig. 17).

Si l'on possédait un terme de comparaison valable, sans doute trouverait-on encore un élément de datation dans l'inclusion dans le parement des murs, à des distances voisinant $0,88 \mathrm{~m}$, des poutres horizontales hautes de $0,16 \mathrm{~m}$, larges de $0,18 \mathrm{~m}$. Recouvertes par les enduits dont le décor n'était pas interrompu, ces poutres invisibles constituaicnt des arases destinécs à assurer l'horizontalité des banchées de maçonnerie.

23 W. J. HenkYen, Korinlische Normalkapilelle, Heidelherg, 1970, p. 11 sq. - R. Awy et P. Gros, La .Maison Carrée de Nimes, $38^{\mathrm{c}}$ Supplément à Galiia, Paris, 1979, p. $132 \mathrm{sq}$. 


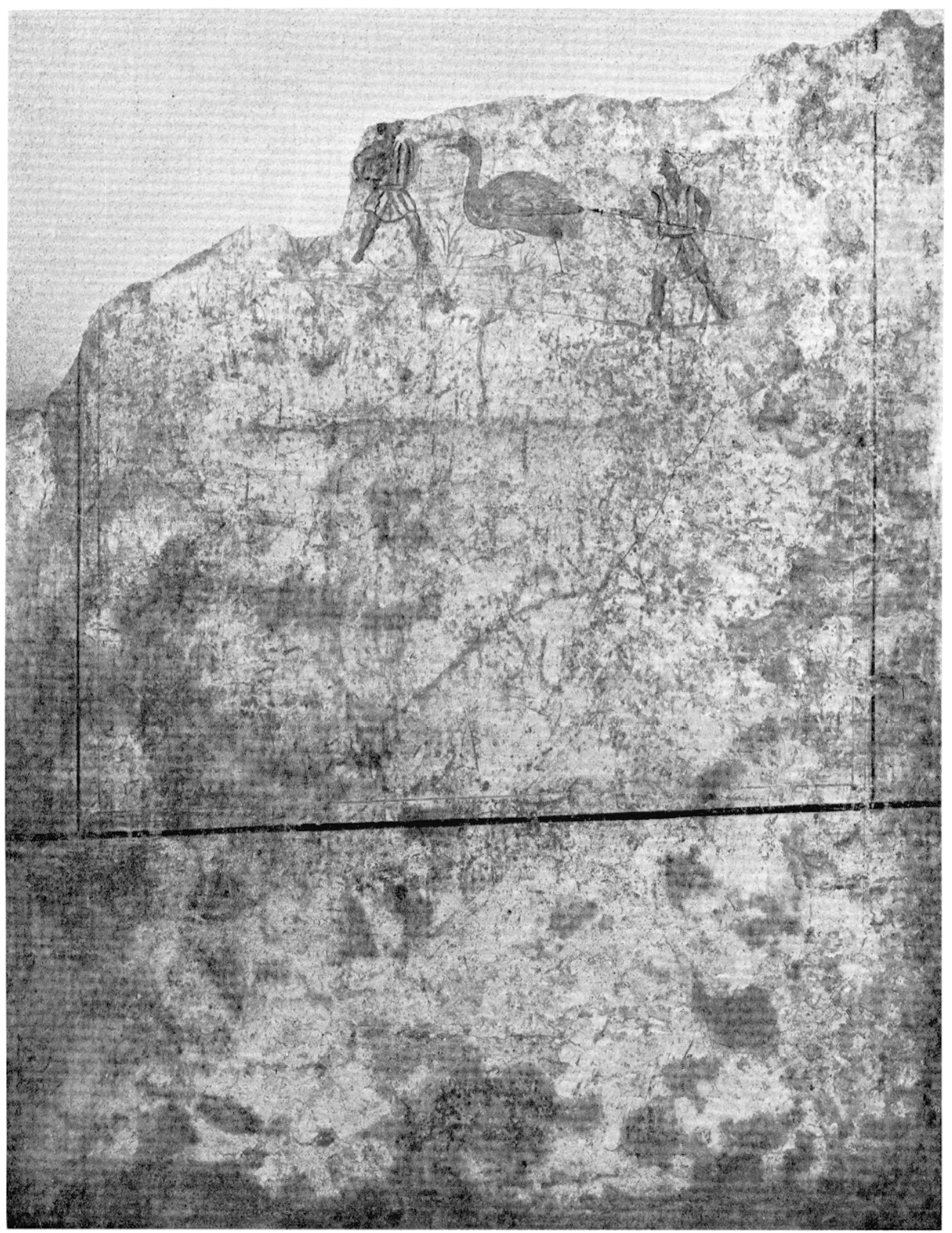

17 Fragmenl. de fresque figurant le combal, des P'ygmées el d'une grue. 
Toute référence au murus gallicus étant exclue, on pourrait être tenté de trouver là un usage qui aurait, par la suite, suggéré celui de couper les murs d'arases de briques pour faire écran à la montée de l'humidité ${ }^{24}$. L'emploi du bois à cet effet serait totalement inefficace. Notons au surplus que cette particularité technique se retrouve aussi bien dans les murs des boutiques que dans les murs orientaux et latéraux de la basilique, apportant, s'il était nécessaire, une confirmation à l'homogénéité de l'insula, bien réalisée en une seule campagne.

Un autre problème chronologique propose des termes contradictoires. Les tambours de colonnes gisant dans les alvéoles du sanctuaire prouvent que la basilique subsistait encore, au moins partiellement, vers 160 . Mais on a également trouvé dans l'alvéole s. les deux demi-chapiteaux scellés sans doute pour servir de banc antérieurement à la construction du sanctuaire. Un hiatus aurait donc existé entre la désaffectation de la basilique et la construction du sanctuaire. L'aménagement du réservoir du Gier aux dépens des locaux annexes de la basilique justifie-t-il ce hiatus? En d'autres termes, la basilique fut-elle désertée dès 121 ? Au cours des 40 années suivantes, ses membrures auraient servi de carrière aux habitants du quartier et de terrain de jeux pour les enfants de la ville haute. Toutcfois, la destruction n'en aurait pas été totale vers 160 puisque, alors seulement, les derniers tambours furent précipités dans les alvéoles en construction. La question méritait d'être posée.

\section{VESTIGES PF́RIPHÉRIQUES}

Le site du sanctuaire a livré d'autres vestiges que l'on ne peut se dispenser de signaler ici.

A. Sous la niche centrale de la paroi occidentale du campus, débordant en avant sur l'espace qui le sépare de la citerne, en arrière sur toute la largeur de l'annexe extérieure, prolongé au n. jusqu'au-delà de la niche outrepassée, est apparu un ensemble de murs, épais seulement de $0,43 \mathrm{~m}$, ornés à leur base d'enduits mouchetés. Cette construction de médiocre ampleur était implantée sur le même axe que l'insula. Suivis sur $16 \mathrm{~m}$ d'o. en e. et de $18 \mathrm{~m}$ du n. au s., ces murs déterminaient des locaux distincts dont n'apparut pas l'économie générale. Il en sortait, en direction de la rue d'Aquitaine, un caniveau réduit à son seul radier de briques posées à plat.

B. 'Toujours sur le même alignement, notons la présence d'un édifice plus important dont l'extrémité orientale a vu son mur amputé d'une partie de son parement pour permettre la construction du mur du sanctuaire. Suivi sur plus de $22 \mathrm{~m}$ de long, le mur $\mathrm{n}$. de cet édifice disparaît d'une part sous le clos du Carmel, de l'autre il s'interrompt au pied de la Maison des Cièdres.

24 A. Acdix et J. Gruyre, Deux murailles antiques, dans Bullelin des Musées et Monuments lyonnais, 1970, 2, p. 37-44. 
C. Par-dessous celle-ci, bordant précisément l'édifice précédent, débouche la rue transversale coupée par le sanctuaire. L'égout de cette rue se déchargeait dans le collecteur au point où celui-ci sortait du sanctuaire. Large de $0,57 \mathrm{~m}$, haut de $1,20 \mathrm{~m}$ sous voûte, avec une clef de $0,32 \mathrm{~m}$, cet égout ne comporte pas de briques.

1). On l'a vu, le dégagement des alvéoles s.-e. du sanctuaire a montré un escalier, large de $3 \mathrm{~m}$, dont des éléments de marches gisaient dans le remblai, tandis que demeure à son pied une dalle de pierre blanche du trottoir. Cet escalier longeait une structure coupéc par le mur s. du sanctuaire, ici en son épaisseur maximale. Il s'agit d'un mur aveugle de 0,60 m, aligné sur la façade des boutiques bordant la rue qui monte des thermes et de l'odéon. Au s., il se prolonge sur $6 \mathrm{~m}$ jusqu'au point où il fut coupé par le collecteur longeant la face s. du sanctuaire. Au n., il se termine à $4,10 \mathrm{~m}$, au contact du mur de l'alvéole. Là, il se coudait à angle aigu pour longer l'escalier selon l'axe oblique de l'insula. Sous le mur o. de l'alvéole existait une porte, ouverte sur un palier de l'escalier, et desservant une terrasse portée par le mur aveugle. Au pied de cette terrasse, côté rue, furent scellées les deux moitiés de chapiteaux décrits plus haut. En granit gris, mêlé de quelques granits roses et de fragments de briques, ce mur était à lits brouillés et irréguliers suivant la pente du sol. Sa longueur n.-s. ne devait pas excéder 15 à $17 \mathrm{~m}$, la plus grande partie étant extérieure à l'empire du sanctuaire.

Amable Audin

N. B. - L'auteur remercie M. PArizot pour les mesures de débil el pression d'eau, Mme Henriette MÉon pour l'étude palynologique, M. Evin pour les complages au radio-carbone, M. LEYGE pour les photos, M. CotTin pour l'identification des mentions topographiques et surtout M. Jacques Greyer pour ses relevés sur le lerrain et la réalisation des plans. 

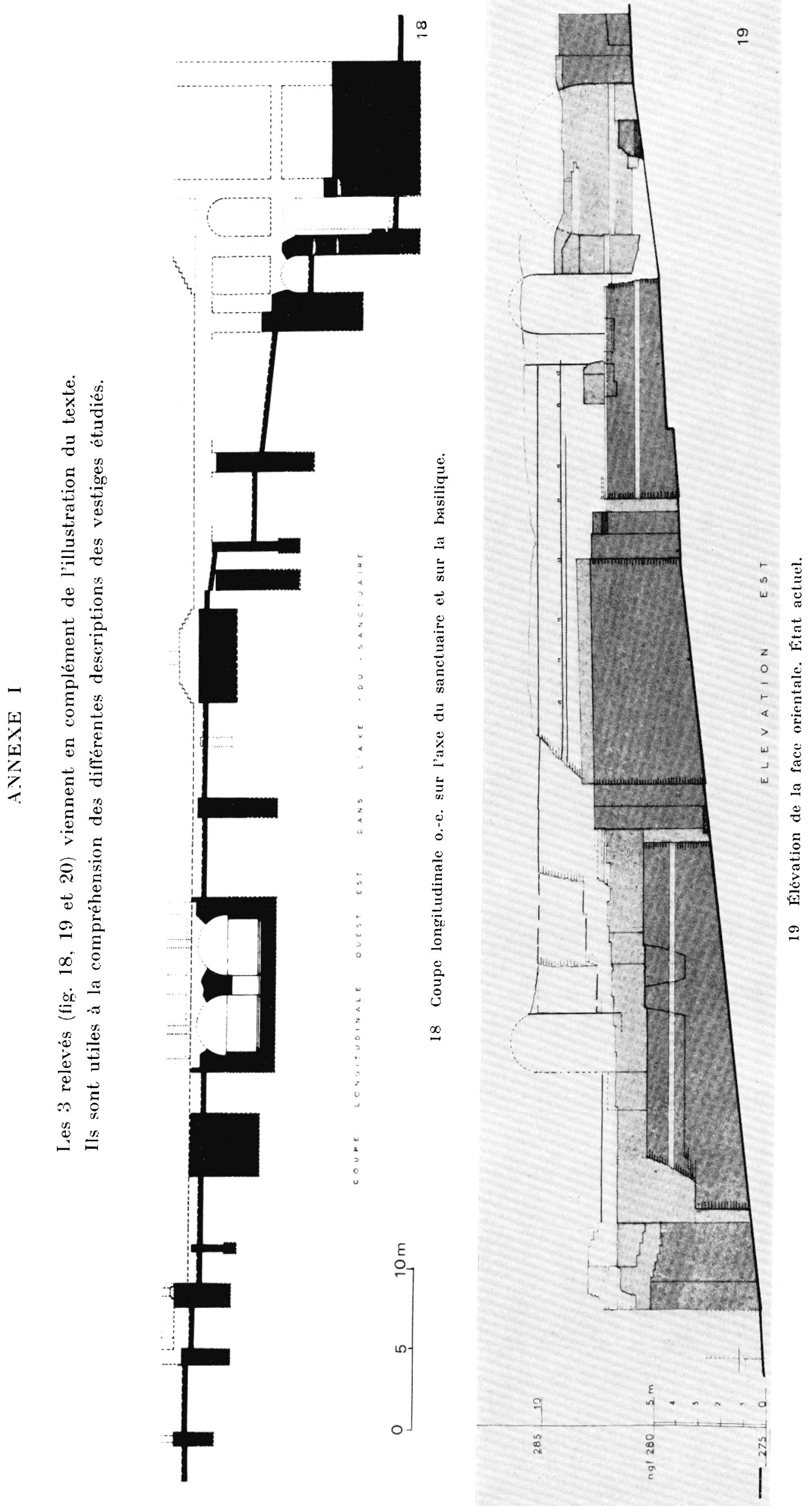


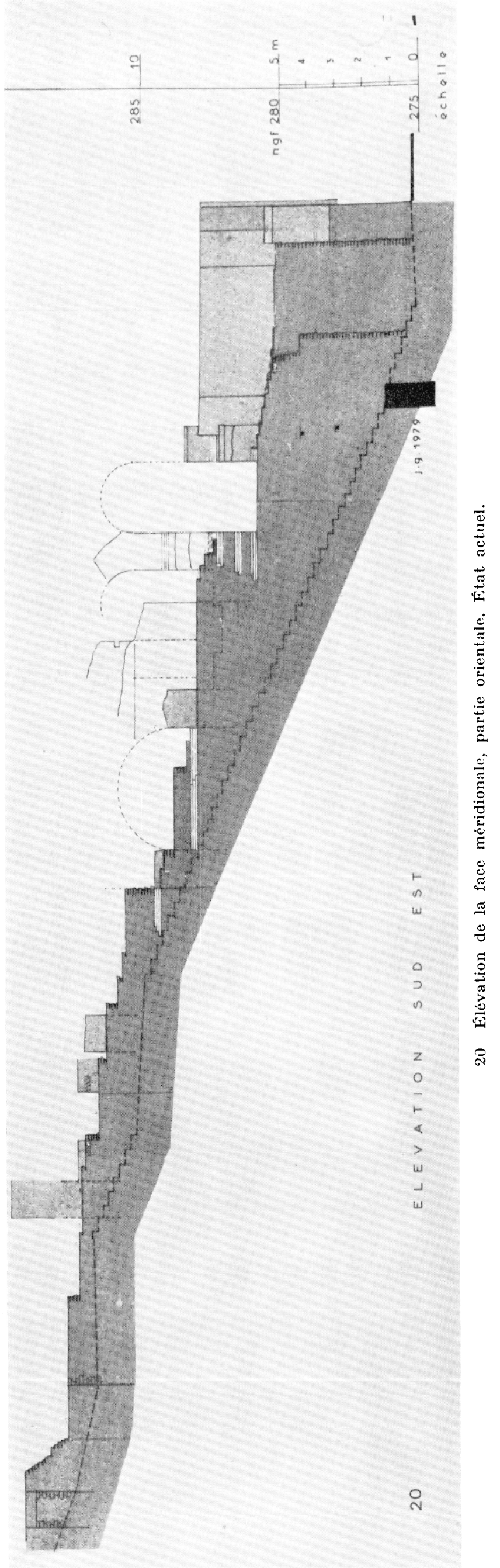




\title{
ANNEXE II
}

\author{
LE SITE PRIMITIF
}

Les fouilles n'ont pas révélé, comme dans la partie centrale du plateau, de fosses d'extraction du lœess. Est-ce à cause de leur destruction par les édifices antiques, ou parce que l'épaisseur moindre rendait cette exlraclion moins fructueuse, ou parce que nos tranchées n'ont pas eu la chance de les atteindre ? Plus simplement, on peut admettre que, avec la construction de l'ensemble basilical, le secteur fut précocement urbanisé, en un temps où le reste du sommet, au-delà de la rue d'Aquitaine, demeurait le domaine des artisans.

\section{Étude palynologique}

Toutefois, les travaux de remise en état des murs du sanctuaire ont retrouvé le lœss en place. Des pollens ont été prélevés juste au-dessus de cette couche. L'étude, réalisée par $\mathrm{M}^{\mathrm{me}}$ Henriette Méon, laisse deviner l'horizon naturel de la colline de Fourvière : à l'angle s.-o. du sanctuaire de Cybèle, au niveau des fondations qui ont entaillé le sol, des prélèvements aux fins d'analyses sporopolliniques ont été effectués le 30 septembre 1978.

Sur cinq échantillons prélevés, un seulement a livré quelques grains de pollcn (une soixantaine seulement) qui peuvent, nous permettre d'avoir une idée du passage à l'époque précédant l'occupation romaine :

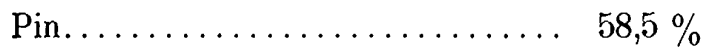

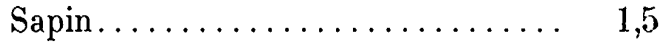

Caryophyllacées.............. $3,5 \%$

Gyprès (?)................ 3,5

Graminées............... 3,5

Composées............... 23,5 Rosacées............... 1,5

Grucifères............... 1,5

Plantes aquatiques.......... 1,5

Il est bien évident qu'il faut être très prudent dans l'interprétation d'un tel résultat.

Les arbres, des Conifères, parmi lesquels domine le Pin, représentent $63,5 \%$ de la végétation. Il ne semble pas que l'on puisse avancer des conclusions climatiques précises. Le paysage végétal relevé semble plutôt le fait de l'influence de l'homme qui avait dû plus ou moins abattre la plupart des arbres de la colline pour s'y installer. Il est aussi difficile de dire si les Pins dont on trouve les pollens poussaient sur la colline ou ont été amenés des environs par le vent. Etaient-ils les restes d'une forêt primitive ou ont-ils été plantés ?

Parmi les plantes herbacées, aucune ne peut être rapportée avec sûreté à des plantes cultivées ou à des plantes qui, habituellement, les accompagnent. On ne peut donc mettre en évidence des traces d'agriculture sur le site.

Les résultats de cette analyse permettent seulement de supposer au moins à proximité du site l'existence d'une forêt de Pins dominante très ouverte ou d'une prairie à bosquets de Pins.

Les traces de plantes aquatiques (Alismatacées) montrent la présence d'eau à proximité (mare ?). 


\section{Datation par radiocarbone}

Des charbons de bois du même prélèvement ont été analysés par M. Evin pour leur datation au radiocarbone : l'âge de ces charbons est fixé à 2100 B.P. \pm 140 ans, c'est-à-dire à 150 avant notre ère et, dans le cas minimal, aux approches du début de notre ère, vraisemblablement plus tôt. Cette détermination vaut naturellement pour l'horizon végétal défini par $\mathrm{M}^{\text {me }}$ Méon.

\section{Traces d'établissements humains}

Ce paysage végétal s'anime grâce à une recherche entreprise par J. Chauffin et moi-même en 1971 à quelque $20 \mathrm{~m}$ en arrière du mur oriental du sanctuaire, en un point où le versant de la colline est très accentué et où les différentes strates en épousent les deux pendages conjugués ${ }^{25}$ :

Strates: A. Culminant à $3,55 \mathrm{~m}$ de profondeur à la cole 384,65 , elle a valeur uniquement géologique, étant constituée par un cailloutis morainique avec apports alpins.

B. Puissante de $0,45 \mathrm{~m}$, elle est faite de lœess rubéfié, mélangé aux terres de la strate précédente qui avaient roulé le long de la pente. Elle ne comporte aucune trace humaine.

G. Simple pellicule de $0,015 \mathrm{~m}$ d'épaisseur, formée aux dépens du substrat. Sa richesse en phosphore et l'absence de vestiges humains suggèrent un stationnement de bétail longuement fréquenté.

D. Puissante de $0,40 \mathrm{~m}$ à $0,50 \mathrm{~m}$, cette terre grasse constitue la première couche archéologique. Elle est coupée par un niveau de circulation feuilleté et très bosselé n'excédant pas $0,005 \mathrm{~m}$ d'épaisseur.

La partie inférieure, D I, haute de $0,16 \mathrm{~m}$ au maximum, révèle de nombreux charbons de résineux, de Pin sylvestre semble-t-il, mêlés de scories, de fer et de masses friables de terre à briques auxquelles les charbons adhèrent encore. Cela rappelle irrésistiblement les enduits gaulois provenant d'aires de foyers et de clayonnages. Un fragment particulièrement caractéristique montre un tel enduit portant empreintes de paille et de branchages. La rareté des éléments de mortier et de briques cuites vient renforcer la dominante gauloise; sans exclure tolalement une présence romaine. Il faut d'ailleurs se souvenir que, il y a un demi-siècle, parut, à courte distance en dessous de ce point, une pièce gauloise en argent à l'image du cavalier. Au surplus D I a fourni deux tessons gris-noir de technique spécifiquement gauloise. Cette strate livre donc un mélange de romain et de gaulois, ce dernier en nette prédominance.

Épaisse de 0,30 m environ, la couche D 2 fournit, d'une part une legulae un bord de couvercle tourné et la trace de calcaires anguleux venus d'une construction en dur, le tout gallo-romain, d'autre part des enduits et des fragments de poteries gaulois. L'apparence est que cette couche, de même nature que la précédente, provient de l'utilisation en remblai aux premiers temps romains de masses tirées de la région plus orientale.

E. Épaisse de $0,01 \mathrm{~m}$, bosselée, feuilletée, brun verdâtre el continue, elle marque la surface de circulation avant la construction des grands édifices romains.

F. Puissante de $1,30 \mathrm{~m}$, elle est constituée par un remblai terrassé mêlant leš matériaux des strates $\mathrm{A}, \mathrm{B}$ et $\mathrm{D}$, tirés de l'entaillement et de l'arasement de la colline, opération qui entraîna l'inversion des couches.

G. Haute de $1,22 \mathrm{~m}$, sans intérêt pour nous, elle résulte du bouleversement occasionné au $\mathrm{XIX}^{\mathrm{e}} \mathrm{s}$. par la construction de maisons modestes, abattues en 1970.

25 J. Chinuffin et A. Audin, Essai de straligraphie archéologique à Fourvière, dans Revue archéologique de l'Est et du Centre-Est, 1972, p. 89-95. 
Faible dans les strates supérieures, le taux des phosphates devient fort dans la couche D et plus encore dans la pellicule $\mathrm{G}$ qui a joué le rôle de filtre. Il ne doit rien à une pollution par infiltration récente. L'hypothèse d'un pacage de bétail prend donc une consistance que renforce la présence d'ossements de bovidés. Toutefois, l'existence d'un camp sur la colline de Fourvière entre le passage de César et l'urbanisation d'Auguste étant avérée, on n'exclura pas l'hypothèse d'un enclos pour la cavalerie romaine.

Malgré son caractère très limité la stratigraphie ainsi réalisée est loin d'être dénuée d'intérêt. Elle fait assister à la constitution, sur un substrat submorainique, d'un sol humique sans apport humain, puis à l'occupation du site par les hommes. Dans un décor de bosquets de Pins sylvestres, ils font paitre leur bétail et résident, aux abords du territoire de notre fouille, dans de légères constructions de clayonnages enduits de loess où ils travaillent le fer. Après un temps de faible occupation qui n'exclut pas une présence romaine, l'arrivée des bâtisseurs entraîne le bouleversement de tout le secteur et l'urbanisation intensive de cette partie de la colline de Fourvière selon les modalités exposées dans le présent article.

A. A. 